\title{
Molecular characterization of autophagic and apoptotic signaling induced by sorafenib in liver cancer cells
}

\author{
María A. Rodríguez-Hernández ${ }^{1 *}$ | Raúl González ${ }^{1 *}$ Ángel J. de la Rosa ${ }^{1} \mid$ \\ Paloma Gallego $^{2 \dagger}$ | Raquel Ordóñez ${ }^{3,4 \dagger}$ | Elena Navarro-Villarán ${ }^{1 \dagger}$ | \\ Laura Contreras $^{1,5 \dagger}$ | Mario Rodríguez-Arribas ${ }^{6,7}$ | Javier González-Gallego ${ }^{3,4}$ \\ José M. Álamo-Martínez ${ }^{1,4,8}$ | Luís M. Marín-Gómez ${ }^{1,8}$ | José A. Del Campo ${ }^{2,4}$ | \\ José L. Quiles ${ }^{9}$ | José M. Fuentes ${ }^{6,7}$ | Jesús de la Cruz ${ }^{1,5}$ | José L. Mauriz ${ }^{3,4}$ |

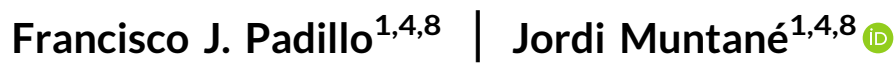

${ }^{1}$ Institute of Biomedicine of Seville (IBiS), Hospital University "Virgen del Rocío"/CSIC/University of Seville, Seville, Spain

${ }^{2}$ Unit for the Clinical Management of Digestive Diseases, Hospital University "Nuestra Señora de Valme”, Seville, Spain

${ }^{3}$ Institute of Biomedicine (IBIOMED), Department of Biomedical Sciences, University of León, León, Spain

${ }^{4}$ Centro de Investigación Biomédica en Red de Enfermedades Hepáticas y Digestivas (CIBEREHD), Madrid, Spain

${ }^{5}$ Department of Genetics, University of Seville, Seville, Spain

${ }^{6}$ Department of Biochemistry, Molecular Biology and Genetics, Faculty of Nursery and Occupational Therapy, University of Extremadura, Cáceres, Spain

${ }^{7}$ Centro de Investigación Biomédica en Red de Enfermedades Neurodegenerativas (CIBERNED), Madrid, Spain

${ }^{8}$ Department of General Surgery, Hospital University "Virgen del Rocío"/CSIC/University of Seville/IBiS/CSIC/University of Seville, Spain

'Institute of Nutrition and Food Technology "José Mataix Verdú", Biomedical Research Center, Department of Physiology, University of Granada, Granada, Spain

\section{Correspondence}

Jordi Muntané, $\mathrm{PhD}$, Instituto de Biomedicina de Sevilla (IBiS), IBiS/“Virgen del Rocío"

University Hospital/CSIC/University of Seville, Seville, Spain, Av. Manuel Siurot $\mathrm{s} / \mathrm{n}$,

41013-Seville, Spain.

Email: jmuntane-ibis@us.es

Funding information

Spanish Ministry of Economy and

Competitiveness, Grant/Award Number:

BFU2016-75352-P; Institute of Health Carlos

III, Grant/Award Numbers: PI15/00034, PI13/ 00021, PI16/00090, PI14/01349; Ministry of

Education, Grant/Award Numbers:

FPU16/05127, FPU12/01433, FPU13/01237;

Andalusian Government, Consejeria de

Economia, Innovacion, Ciencia y Empleo,

Grant/Award Number: CTS-6264; Consejeria

de Igualdad, Salud y Politicas Sociales, Grant/

Award Numbers: PI-00025-2013, PI-0127-

2013, PI-0198-2016; Ministry of Health,

Grant/Award Numbers: PI13/00021, PI14/

01349, PI15/00034, PI16/00090
Sorafenib is the unique accepted molecular targeted drug for the treatment of patients in advanced stage of hepatocellular carcinoma. The current study evaluated cell signaling regulation of endoplasmic reticulum (ER) stress, c-Jun-N-terminal kinase (JNK), Akt, and 5'AMP-activated protein kinase (AMPK) leading to autophagy and apoptosis induced by sorafenib. Sorafenib induced early (3-12 hr) ER stress

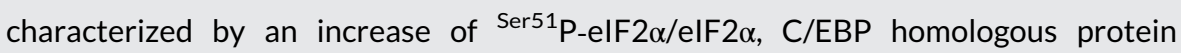
(CHOP), IRE1 $\alpha$, and SXBP1, but a decrease of activating transcription factor 6 expression, overall temporally associated with the increase of ${ }^{\text {Thr183,Tyr185} P-J N K 1 / 2 / ~}$ JNK1/2, ${ }^{\text {Thr172 } P-A M P K \alpha, ~}{ }^{\text {Ser4133P-Foxo3a, }}{ }^{\text {Thr308 } P-A K t / A K t ~ a n d ~}{ }^{\text {Thr } 32} \mathrm{P}$-Foxo3a/Foxo3a ratios, and reduction of ${ }^{S e r 2481} \mathrm{P}$-mammalian target of rapamycin (mTOR)/mTOR and protein translation. This pattern was related to a transient increase of $\mathrm{tBid}, \mathrm{Bim} \mathrm{EL}_{\mathrm{L}}$, Beclin-1, Bcl-xL, Bcl-2, autophagy markers, and reduction of myeloid cell leukemia-1 (Mcl-1) expression. The progressive increase of $\mathrm{CHOP}$ expression, and reduction of ${ }^{\text {Thr }}{ }^{08} \mathrm{P}$-AKt/AKt and ${ }^{\mathrm{Ser} 473} \mathrm{P}-\mathrm{AKt} / \mathrm{AKt}$ ratios were associated with the reduction of autophagic flux and an additional upregulation of Bime $\mathrm{EL}_{\mathrm{L}}$ expression and caspase-3 activity ( $24 \mathrm{hr}$ ). Small interfering-RNA (si-RNA) assays showed that Bim, but not Bak and Bax, was involved in the induction of caspase-3 in sorafenib-treated HepG2 cells.

*María A. Rodríguez-Hernández and Raúl González Contreras contributed equally to this work.

${ }^{\dagger}$ Paloma Gallego, Raquel Ordóñez, Elena Navarro-Villarán and Laura Contreras contributed equally to this work. 
Sorafenib increased autophagic and apoptotic markers in tumor-derived xenograft model. In conclusion, the early sorafenib-induced ER stress and regulation of JNK and AMPK-dependent signaling were related to the induction of survival autophagic process. The sustained drug treatment induced a progressive increase of ER stress and PERK-CHOP-dependent rise of Bim $_{E L}$, which was associated with the shift from autophagy to apoptosis. The kinetic of Bim $\mathrm{EL}_{\mathrm{L}}$ expression profile might also be related to the tight balance between AKt- and AMPK-related signaling leading to Foxo3adependent BIM $\mathrm{EL}$ upregulation.

\section{KEYWORDS}

5'AMP-activated protein kinase (AMPK), apoptosis, autophagy, $\mathrm{Bcl}-2$, endoplasmic reticulum stress, mammalian target of rapamycin (mTOR)

\section{1 | INTRODUCTION}

Hepatocellular carcinoma ( $\mathrm{HCC}$ ) is the most common type of liver cancer and the second most frequent cause of cancer-related death worldwide (Llovet et al., 2016; Torre et al., 2015). HCC develops within a cirrhotic liver in $80 \%-90 \%$ of cases that influences therapeutic decisions (Fattovich, Stroffolini, Zagni, \& Donato, 2004; Sanyal, Yoon, \& Lencioni, 2010). The difficulty in forming an early diagnosis, at the first stage of the disease, contributes to the poor response of patients to current clinical treatments. Currently, only one-third of newly diagnosed patients with $\mathrm{HCC}$ are an at early stage ( 0 or A), according to the Barcelona Clinic Liver Cancer (BCLC) staging system, and are eligible for potential curative therapies such as local ablation, resection, or orthotopic liver transplantation with a 5-year survival rate of 50\%-80\% (Bruix, Reig, \& Sherman, 2016). The recommended first-line treatment for patients with locally advanced/ metastatic disease (BLCL C) is sorafenib with a mean overall survival of 11 months (Cheng et al., 2009; Llovet et al., 2008).

Sorafenib inhibits tyrosine kinase receptors such as vascular endothelial growth factor receptor (VEGFR) 2, VEGFR 3, plateletderived growth factor receptor- $\beta$ (PDGFR- $\beta$ ), Flt3 and c-Kit, as well as molecular components of the Raf/MEK/extracellular signal-regulated kinase (ERK) signaling pathway (Cervello et al., 2012). Different studies have suggested that the increased susceptibility to cell death by sorafenib is associated with down-regulation of cell survival pathways in hepatoma cells (Prieto-Dominguez et al., 2016). In particular, Chen et al. (2010) showed that sorafenib enhanced TRAIL-induced cell death through SH2 domain-containing tyrosine phosphatase (SHP-1)-dependent reduction of signal transducers and activators of transcription type 3 (STAT3) phosphorylation ( ${ }^{\mathrm{Ty} 705}$ STAT3) and related proteins members myeloid cell leukemia-1 (Mcl-1), survivin, and cyclin D1 in hepatoma cells. Sorafenib-induced cell death is also related to upregulation of the proapoptotic "BH3-domain only" PUMA and BIM, as well as a decrease of Mcl-1 and survivin (Fernando et al., 2012). It has also been shown that c-Jun-N-terminal kinase (JNK)-dependent GADD45 $\beta$ (Ou et al., 2010) and PUMA (Fernando et al., 2012) expressions are also involved in the proapoptotic properties of sorafenib in HCC cells. Shimizu et al. (2012) showed that sorafenib enhanced autophagy, pharmacological inhibition due to which increased apoptosis and decreased cell viability in sorafenib-treated Huh7, HLF, and PLC/PRF/5 cells. However, other studies did not find a relationship between autophagy induction and resistance to treatment in sorafenibtreated HCC cells (Fischer, Wang, Vlada, Kim, \& Behrns, 2014). The current study showed that the induction of autophagy in sorafenibtreated HepG 2 cells is related to IRE- 1 and eIF $2 \alpha$-dependent ER stress, JNK and 5'AMP-activated protein kinase (AMPK)-dependent signaling. The shift from autophagy to apoptosis is related to a decline of Beclin-1, $\mathrm{Bcl}-2, \mathrm{Mcl}-1, \mathrm{Bcl}-\mathrm{xL}, \mathrm{Bcl}-2$, and $\mathrm{tBid}$ and the increase of proapoptotic BimEL, Bak, and Bax.

\section{MATERIAL AND METHODS}

\subsection{Chemical and reagents}

Sorafenib (Ref FS10808; Carbosynth Limited, Berkshire, UK) was dissolved in dimethyl sulfoxide as stock solution (100 mM). 3-MethylAdenine (3MA; Ref M9281), chloroquine (CQ; Ref C6628), SP600125 (Ref S5567), and dorsomorphin (Ref P5499) were obtained from Sigma-Aldrich (Sant Louis, MO).

\section{2 | Primary human hepatocytes, cell lines, and culture conditions}

Human hepatocytes were prepared from liver biopsies obtained from three patients (two females and one male, aged $66 \pm 3.0$ years) submitted to surgical resection for liver tumors after obtaining the patients' written consent. Hepatocytes isolation was based on a two-step collagenase procedure (Pichard et al., 2006). HepG2 and Hep3B cell lines were obtained from the American Type Culture Collection (LGC Standards, S.L. U., Barcelona, Spain). Huh7 cell line was purchased from Apath, LLC (Brooklyn, NY). Cell lines were selected according to their p53 content: HepG2 (WT p53 expression), Huh7 (p53 mutated isoform, codon 220), and Hep3b (nonsense p53 mutation). All lines were negative for mycoplasma contamination. The cells were cultured in minimum essential medium (MEM) with Earle's salts with L-glutamine (Ref E15-825, PAA) with $10 \%$ fetal bovine serum (FBS; F7524, Sigma-Aldrich, Lot No: 
022M3395, endotoxin < $0.2 \mathrm{EU} / \mathrm{ml}$ ), sodium pyruvate ( $1 \mathrm{mM}$; Ref S11003, PAA), nonessential amino acids (Ref M11-003, PAA), penicillin-streptomycin solution $(100 \mathrm{U} / \mathrm{ml}-100 \mu \mathrm{g} / \mathrm{ml}$; P11-010, PAA), at $37^{\circ} \mathrm{C}$ in a humidified incubator with $5 \% \mathrm{CO}_{2}$. The cells were cultured at a cell density of 100,000 cells $/ \mathrm{cm}^{2}$, treatment added 24 after plating, and lysates were obtained at different time points after treatments. Sorafenib was administrated at different concentrations ( $1 \mathrm{nM}-100 \mu \mathrm{M})$. Additional experimental interventions, such as 3MA $(5 \mu \mathrm{M})$ and CQ (50 $\mu \mathrm{M})$, were preadministered $(2 \mathrm{hr})$, and dorsomorphin $(5 \mu \mathrm{M})$ was coadministered with sorafenib. The Biobank of the Institution approved the use of primary biopsies of patients for the present research (Ref. no 33140031, April 1, 2014).

\section{3 | Effect of sorafenib administration on tumor growth in a xenograft mouse model}

Sixty male Hsd:Athymic Nude-Foxn1 ${ }^{\text {nu }}$ mice (Harlan Laboratories, Barcelona, Spain), aged 4 weeks (weighing 18-22 g), were randomly distributed in three groups according to the subcutaneous implantation of HepG2, Hep3b, and Huh7. Cells $\left(10 \times 10^{6}\right)$ were diluted in matrigel (Ref 356231, Lot 36821, BectonDickinson, NJ) and administered subcutaneously into the right flank of the mice. Each experimental group was subdivided into the group receiving sorafenib $(200 \mathrm{mg} / \mathrm{kg})$ and the group receiving a solvent, which was constituted by ethanol:Koliphor EL (C5135, Sigma-Aldrich):0.9\% $\mathrm{NaCl}$ (1:1:6). Sorafenib or solvent was administered daily by oral gavage when the tumor diameter grew to $5 \mathrm{~mm}$ (11 days) and ended at the sacrifice of animals when tumor diameter was $15 \mathrm{~mm}$ (24 days). The tumor volume was calculated using the formula: $V=[($ length $) \times($ width $) \times$ $($ depth) $\times \pi] / 6$. All animal care and experimentation conformed to the Guide for the Care and Use of Laboratory Animals published by the National Academy of Sciences. The Ethical Committee of the Institution approved the in vivo experiments (Ref. no CEP2104 PI/016, January 30, 2014).

\section{4 | Immunohistochemistry}

Tumor tissue sections $(5 \mu \mathrm{m})$ were obtained to analyze the expression of $\alpha$-smooth muscle actin ( $\alpha$-sma), Ki67, CD31, and CD34 by immunohistochemistry. Sections were deparaffinized, hydrated through graded ethanol steps, briefly rinsed in water, and blocked at room temperature using TBSA-BSAT $(10 \mathrm{mM}$ Tris, $0.9 \% \mathrm{NaCl}, 0.02 \%$ sodium azide, $2 \%$ bovine serum albumin and $0.1 \%$ Triton-X100). Slices were incubated overnight at room temperature with primary antibodies against 1:250 $\alpha$ sma (ab5694; Abcam, Cambridge, UK), 1:500 (Ki67, IR626; DAKO Glostrup, Denmark), 1:50 CD31 (ab28364; Abcam), and 1:200 CD34 (ab64480; Abcam), followed by incubation with the corresponding secondary antibodies, either Alexa 488 anti-rabbit IgG (A11008; Invitrogen, Carlsbad, CA, Spain) or Alexa 488 anti-mouse IgG (A11001; Invitrogen), for $5 \mathrm{hr}$ diluted in TBSA-BSAT (1:500). Nuclear staining was performed using DRAQ-5th (red fluorescent cell-permeable DNA probe; Biostatus Limited, Loughborough, UK). Immunofluorescence analysis was performed using an Olympus BX61 microscope (Tokyo, Japan). Fluorescence quantification was performed using Leica Application Suite Advanced Fluorescence software and ImageJ software (Wetzlar, Germany).

\subsection{Ultrastructural analysis by transmission electronic microscopy}

Treated and control cells were isolated and prefixed in $1.5 \%$ formaldehyde in $1 \%$ cacodylate buffer, $\mathrm{pH} 7.4$, for $2 \mathrm{hr}$ at $4^{\circ} \mathrm{C}$. After three washes in cacodylate buffer, the extracts were fixed in $1 \%$ osmium tetroxide for $60 \mathrm{~min}$ at $0-4^{\circ} \mathrm{C}$. The samples were dehydrated in graded ethanol and embedded in Epon resin. After overnight incubation at $65^{\circ} \mathrm{C}$, ultrathin sections $(70 \mathrm{~nm})$ were cut with a diamond knife using an Ultracut $S$ ultramicrotome and placed on 200-mesh copper grids. All sections were stained with uranyl acetate, counterstained with lead citrate, and viewed using a Carl Zeiss (Oberkochen, Germany) EM10C electron microscope at 4,646x, 10,000x, and 46,460x magnifications in the Biomedical Research Center at the University of Granada's Health Technology Park.

\subsection{Measurement of cell death}

Caspase-3-associated activities were determined using CaspaseGlo® 3 Assay Systems (G8091; Promega, Madison). Cells were treated with Caspase-Glo ${ }^{\circledR} 3$ in an "add-mix-measure" format resulting in cell lysis, caspase-3-dependent cleavage of the substrate and generation of a "glow-type" luminescent signal. The signal generated was proportional to the amount of caspase activity. The values are extrapolated into a calibration curve included in the assay. Cell death in tissue sections was determined using the DeadEnd ${ }^{\mathrm{TM}}$ fluorometric terminal deoxynucleotidyl transferase mediated dUTP nick-end labeling (TUNEL) System (G3250, Promega) that measures the fragmented DNA of apoptotic cells by catalytically incorporating fluorescein-12-dUTP at 3'-OH DNA ends using the enzyme terminal deoxynucleotidyl transferase (TdT), which forms a polymeric tail using the principle of the TUNEL assay. The fluorescein-12-dUTPlabeled DNA was visualized using an Olympus BX61 microscope. Fluorescence quantification was performed using Leica Application Suite Advanced Fluorescence software and the ImageJ software.

\section{7 | Cell proliferation}

The measurement of bromodeoxyuridine (BrdU) incorporation was used as marker of cell proliferation (Ref. 11647229001; Roche Diagnostics, Indianapolis, IN). Cells were seeded in 96-well plates at low density $\left(12,500\right.$ cells $\left./ \mathrm{cm}^{2}\right)$. Two hours before sampling, $20 \mu \mathrm{l}$ of $\mathrm{BrdU}(10 \mu \mathrm{M})$ was added to the cultures. DNA was denaturalized with $200 \mu \mathrm{l}$ FixDenat solution included in the commercial assay for $30 \mathrm{~min}$ at room temperature. After removal, the cells were incubated with $100 \mu \mathrm{l}$ monoclonal anti-BrdU antibody HRP conjugated for $90 \mathrm{~min}$ at room temperature. Afterwards, the cells were washed with PBS and incubated with $100 \mu \mathrm{l}$ reveling solution including hydrogen peroxide, luminol and 
4-iodophenol for $15 \mathrm{~min}$ at room temperature. Absorbance was measured at $370 \mathrm{~nm}$ using an Infinite 200 PRO Microplate Reader (TECAN, Männedorf, Switzerland).

\section{8 | Assessment of protein expression of ER stress, autophagy, and apoptosis markers}

Cells or tumor tissues were treated with lysis solution including $50 \mathrm{mM}$ HEPES pH. 7.5, $5 \mathrm{mM}$ ethylenediaminetetraacetic acid (EDTA), $150 \mathrm{mM} \mathrm{NaCl}, 1 \% \mathrm{NP}-40$, a commercial proteases inhibitor cocktail (P8340, Sigma-Aldrich), $1 \mathrm{mM}$ phenylmethanesulfonyl fluoride (PMSF), $1 \mathrm{mM} \mathrm{NaF}$, and $1 \mathrm{mM} \mathrm{Na}_{3} \mathrm{VO}_{4}$. Protein expression were determined by SDS-PAGE coupled to western-blot analysis. Proteins $(50-100 \mu \mathrm{g})$ were separated by Any kD ${ }^{\mathrm{TM}}$ Criterion ${ }^{\mathrm{TM}} \mathrm{TGX}$ Stain-Free ${ }^{\mathrm{TM}}$ Protein Gel, 18 well, $30 \mu \mathrm{l}$ (\#5678124; BioRad, Hercules, CA) and transferred to polyvinylidene difluoride (PVDF) membranes. The system uses stain-free technology, which is a method that appears to be more reliable as a protein loading control than measurement of housekeeping proteins (Colella et al., 2012). The membranes were incubated with the corresponding commercial primary and secondary antibodies coupled to horseradish peroxidase revealing protein content by Clarity $^{\mathrm{TM}}$ Western ECL substrate (Ref 170-5061; BioRad) and analyzed in a ChemiDoc ${ }^{\text {TM }}$ Touch Imaging System. Antibodies for western-blot, tBid (\#2002), elF2 $\alpha$ (\#5324), inositol-requiring enzyme 1 $\alpha$ (IRE1 $\alpha, \# 3294)$, p62 (\#5114),

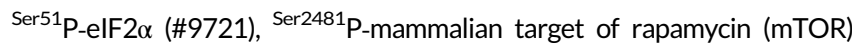

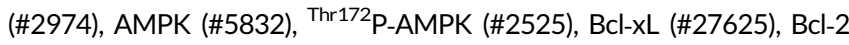
(\#2872), Bax (\#5023), Bak (\#12105), Bim (\#2933), FoxO3a (\#2497),

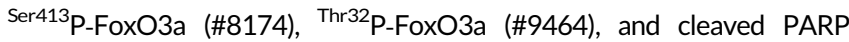
(\#9542) were commercially obtained from Cell Signaling Technology (Danvers, MA); activating transcription factor 6 (ATF6, ab122897) was purchased from Abcam; LC3 (PM036) was purchased from MBL International (Woburn, MA); Beclin-1 (sc-11427), GADD153/CHOP (sc-575) and AKt (sc-1618) were obtained from Santa Cruz Biotechnol-

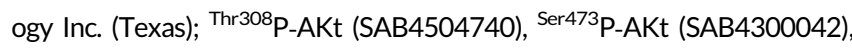
JNK1/2 (SAB4200176), Thr183,Tyr185P-JNK1/2 (J4644) and Mcl-1 (SAB4501843) were obtained from Sigma-Aldrich. The corresponding secondary antibodies anti-rabbit (sc-2004), anti-mouse (sc-2005) and anti-goat (sc-2768) IgG-HRP labled were purchased from Santa Cruz. Densitometric analysis was performed using the software Image Lab 6.0 of BioRad.

\section{9 | XBP1s/XBP1 mRNA expression ratio by qRT-PCR}

RNA was isolated using TRIsure Reagent (BIO-38033; Bioline Reagents Ltd., London, UK), and submitted to retrotranscription (iScript ${ }^{\mathrm{TM}} \mathrm{cDNA}$ Synthesis Kit \#1708891; BioRad) and amplification by real-time quantitative reverse transcription polymerase chain reaction (RT-qPCR) (iTaq ${ }^{\text {TM }}$ Universal SYBR ${ }^{\circledR}$ Green Supermix \#1725142; BioRad). RT-PCR was performed in ViiA ${ }^{\mathrm{TM}} 7$ Real-Time PCR System (Applied Biosystems, Thermo Fisher Scientific, Waltham, MA) with a QuantumStudio ${ }^{\text {TM }}$ Real Time PCR Software. Reactions were performed in 96-well plates with an optical sealing tape (Thermo Fisher Scientific) in $25 \mu$ total volume containing SyberGreen Mix and the corresponding cDNA. Histone 3 (H3B3) was used as internal control in parallel for each run. The conditions for amplification were as follows: polymerase activation and a DNA denaturation step of $95^{\circ} \mathrm{C}$ for $40 \mathrm{~s} ; 30$ cycles of amplification composed of a denaturation step of $95^{\circ} \mathrm{C}$ for $20 \mathrm{~s}$ and annealing/ extension+plate read at the optimized temperature of each couple of primers $\left(54-60^{\circ} \mathrm{C}\right)$ for $60 \mathrm{~s}$; and a final melt curve analysis of $95^{\circ} \mathrm{C} 15 \mathrm{~s}, 60^{\circ} \mathrm{C} 60 \mathrm{~s}$ and $95^{\circ} \mathrm{C} 15 \mathrm{~s}$. All primers were designed using online Primer3 software Primer3input and purchased from Eurofins (Eurofins Genomics):

$\begin{array}{lll}\text { Primer } & \text { Sequence } \text { 5' }^{\prime} \mathbf{3}^{\prime} & \mathrm{Tm},{ }^{\circ} \mathrm{C} \\ \text { XBP1s Fw } & \text { CGG GTC TGC TGA GTC CGC AGC AG } & 69.6 \\ \text { XBP1 Fw } & \text { GCA GGT GCA GGC CCA GTT GTC AC } & 67.8 \\ \text { XBP1s Rv } & \text { CCC CAC TGA CAG AGA AAG GGA GG } & 66 \\ \text { XBP1 Rv } & \text { CCC CAC TGA CAG AGA AAG GGA GG } & 66\end{array}$

\subsection{0 | si-RNA interference}

HepG2 cells were seeded in 6-well plates the day before transfection to reach a confluency of $60 \%$ in $24 \mathrm{hr}$. Transfection was conducted with the siTran 1.0 Transfection Reagent (siTranTM si-RNA transfection; Origene, Rockville, MD) according to recommendations of the manufacturer. The si-RNA of IRE1 $\alpha$, pancreatic ER kinase (PKR)-like ER kinase (PERK), and ATF6 were synthesized by Origene. Their targeting sequences can be accessed from the Origene webpage with the references SR301457 (IRE1 $\alpha$, NM_001433), SR306267 (PERK, NM_004836), and SR307883 (ATF6, NM_007348). A nontargeting si-RNA (SR30004, Trilencer-27 Universal Scrambled Negative Control si-RNA Duplex) also purchased from Origene was used as negative control. Sorafenib was added $48 \mathrm{hr}$ after transfection.

si-RNA for knock-down Bax (L-003308-01-0005), Bak (L-00330500-0005), Bim (L-004385-00-0005), FoxO3a (L-003007-00-0005), and scramble (D-001810-10-05) were obtained from Dharmacon (Lafayette, CO) and used in HepG2 cells cultured at 20,000 cells $/ \mathrm{cm}^{2}$. si-RNA ( $25 \mathrm{nM})$ were mixed with the transfection reagent DharmaFECT1 (Ref T-2001-02) for $20 \mathrm{~min}$ at room temperature and transferred to culture medium without antibiotic/antimycotic solution and kept for $24 \mathrm{hr}$ prior to treatment. Afterwards, transfected cells were maintained until the end of the experiment following the manufacturer's recommendations.

\subsection{1 | pDest-LC3-GFP-mCherry transient transfection and detection of punctuate LC3-positive structures}

Expression of $\mathrm{pH}$-sensitive sensor constructed as a tandem fusion of mCherry and GFP to LC3B (pDest-LC3-GFP-mCherry) was used to monitor autophagy in HepG2 cells (kindly provided by Dr. Terje Johansen). The GFP tag is acid-sensitive, whereas the mCherry tag is acid-insensitive. Yellow merge punctate structures indicate autophagosomes which neutral $\mathrm{pH}$ allows both tags emit 
fluorescent light resulting in a yellow staining. Subsequent fusion of autophagosomes with lysosomes results in red-positive acidic vacuoles, where the green fluorescence from GFP is lost. HepG2 cells were seeded in 24-well plates with coverslips at $2 \times 10^{5} \mathrm{cells} / \mathrm{ml}$, and $500 \mu \mathrm{l}$ of antibiotic free medium per well. After $24 \mathrm{hr}$, the cells were transiently transfected with pDest-LC3. GFP-mCherry construct with Lipofectamine 2000 (Ref 11668027; Invitrogen), according to the manufacturer's protocol $(2 \mu \mathrm{l}$ of Lipofectamine and $3 \mu \mathrm{g}$ of plasmid per well). The following day, the cells were treated with Earle's balanced salt solution (Sigma, E2888) and $\mathrm{CQ}(50 \mu \mathrm{M})$ as negative and positive control, respectively. Sorafenib was administered at $10 \mu \mathrm{M}$ and $100 \mu \mathrm{M}$. All these treatments lasted for 6, 12, or $24 \mathrm{hr}$. Once the treatments were finished, the medium was recovered, and the cells were washed with phosphate saline buffer (PBS1X). The cells were immediately fixed by using a $4 \%(\mathrm{w} / \mathrm{v})$ paraformaldehyde solution in PBS1X for 30 min. Nuclei were stained with Hoechst 33342 and coverslips were mounted in slides with Fluoromount G (Invitrogen, 00-4958-02). Fluorescence images were obtained with an inverted microscope (IX-51, Olympus) provided with a DP-70 camera. Image analyses were performed using IFDOTMETER (RodriguezArribas et al., 2016) and ImageJ. The quantifications of the number of mCherry positive, corresponding to red-positive acidic autophagolysosome vacuoles, and GFP+mCherry positive, corresponding to yellow-positive autophagosome, were both measured at 6, 12, and $24 \mathrm{hr}$.

\subsection{2 | Assessment of protein translation}

The protocol adapted for polysome preparation of HepG2 cells was the one we routinely employ for yeast cells (Kressler, de la Cruz, Rojo, \& Linder, 1997). Briefly, HepG2 cells were grown to $80 \%$ confluency in $175 \mathrm{~cm}^{2}$ dishes as described above. Normally, two dishes were used per condition assayed. Before harvesting the cells, $200 \mu \mathrm{g} / \mathrm{ml}$ cycloheximide was added and incubated for $5 \mathrm{~min}$ at $37^{\circ} \mathrm{C}$. Each dish was then placed on ice, the medium was collected, and the cultures washed twice with PBS without $\mathrm{Ca}^{2+}$ and $\mathrm{Mg}^{2+}$ containing $200 \mu \mathrm{g} / \mathrm{ml}$ cycloheximide. Then, $600 \mu \mathrm{l}$ of lysis buffer $(10 \mathrm{mM}$ Tris- $\mathrm{HCl}, \mathrm{pH} 7.4,150 \mathrm{mM} \mathrm{NaCl}, 10 \mathrm{mM}$ $\mathrm{MgCl}_{2}, 200 \mu \mathrm{g} / \mathrm{ml}$ cycloheximide, $200 \mu \mathrm{g} / \mathrm{ml}$ heparin, $2 \mathrm{mM}$ dithiothreitol (DTT), 0.5\% NP40) was added to one dish, cells were scraped, and transferred to the second dish. After scraping the cells corresponding to the second dish, the whole juice was transferred to a $1.5 \mathrm{ml}$-Eppendorf tube. The tubes were incubated at $4^{\circ} \mathrm{C}$ with gentle end-over-end rotation for $10 \mathrm{~min}$ and then centrifuged at $16,000 \mathrm{~g}$ for $8 \mathrm{~min}$ at $4^{\circ} \mathrm{C}$ in a refrigerated microfuge. The corresponding supernatants were recovered, and the $A_{260}$ was measured using a NanoDrop ND-1000 Spectrophotometer (Thermo Fisher Scientific). About 10 absorption units of $A_{260}$ were layered on top of $7 \%-50 \%(w / v)$ sucrose gradients prepared in $50 \mathrm{mM}$ Tris-acetate, $\mathrm{pH} 7.5,50 \mathrm{mM} \mathrm{NH}_{4} \mathrm{Cl}, 12 \mathrm{mM} \mathrm{MgCl}_{2}$, $1 \mathrm{mM}$ DTT. The gradients were centrifuged at $260,110 \mathrm{~g}(39,000 \mathrm{rpm})$ in a Beckman SW41 rotor at $4^{\circ} \mathrm{C}$ for $2 \mathrm{hr} 45 \mathrm{~min}$. To dissociate the vacant $80 \mathrm{~S}$ ribosomes, high-salt conditions were achieved by adding $\mathrm{NaCl}$ to a final concentration of $0.25 \mathrm{M}$ in the gradients. Gradient analysis was performed with an ISCO UA-6 system (Isco, Inc. Lincoln, NE) equipped to continuously monitor the $A_{254}$.

\subsection{Expression of Bim, Bak, and Bax in Beclin-1 immunoprecipitated fraction}

A volume of the cell lysate $(500 \mu \mathrm{g}$ protein) was mixed with immunoprecipitation buffer $(20 \mathrm{mM}$ Tris- $\mathrm{HCl}$ pH 7.5, 1\% Triton $X-100,150 \mathrm{mM} \mathrm{NaCl}, 10 \%$ glycerol, $1 \mathrm{mM} \mathrm{Na} \mathrm{VO}_{4}, 50 \mathrm{mM} \mathrm{NaF}$, $2 \mathrm{mM}$ EDTA, $1 \mathrm{mM}$ PMSF, commercial proteases inhibitor cocktail (P8340, Sigma-Aldrich), and $2 \mu \mathrm{g}$ of anti-Beclin-1 antibodies (sc-48341, Santa Cruz Biotechnology Inc.) at $4^{\circ} \mathrm{C}$ overnight. Afterward, protein $\mathrm{G}$ Sepharose (35 II; GE Healthcare) was added, agitated for $3 \mathrm{hr}$, and the washed resin was loaded onto a $10 \%$ SDS-PAGE electrophoresis gel. The expression of Bim, Bak, and Bax was assessed by western-blot analysis as described above. The immunoprecipitation using unspecific mouse IgG (sc-2025; Santa Cruz Biotechnology) and anti-Beclin-1 antibodies were run in parallel. The expression of Bim, Bak, and Bax has also been measured in cell lysate (50 $\mathrm{\mu g}$ proteins).

\subsection{4 | Statistical analysis}

All results are expressed as the mean \pm standard error of the mean of independent experiments $(n=4-10)$. Data were compared using the analysis of variance with the least significant difference's test as posthoc multiple comparison analysis (homogeneity of variances) or GamesHowell analysis (nonhomogeneity of variances). If Shapiro-Wilks's test showed nonnormal distribution of data, nonparametric Kruskal-Wallis coupled to U Man-Whitney posthoc analysis with Finner's correction was done. The level of significance was set at ${ }^{*} p \leq 0.05,{ }^{* *} p \leq 0.01$, ${ }^{* * *} p \leq 0.001$. The groups significantly different $(p \leq 0.05)$ were indicated with different letters.

\section{3 | RESULTS}

\subsection{Sorafenib administration reduced tumor cell growth in xenograft mouse model}

The administration of sorafenib tosylate $(30-100 \mathrm{mg} / \mathrm{kg})$ orally once daily reduced growth and angiogenesis while promoting apoptosis in tumors developed by PLC/PRF/5 (Liu et al., 2006) and patient-derived cell lines (Huynh et al., 2009) subcutaneously implanted in severe combined immunodeficient mice. Sorafenib tosylate $(200 \mathrm{mg} / \mathrm{kg})$ was administered to nude mice once daily when the diameter of the tumors reached $5 \mathrm{~mm}$. The weight of animals did not change with the treatment (Supporting Information Figure S1a). The administration of sorafenib reduced tumor volume (Figure $1 \mathrm{a}$ and Supporting Information Figure S1b) in parallel to an increase of caspase-3 activity (Figure 1b), cleaved PARP (Figure 1c) and autophagic markers (Beclin-1 and LC3II/LC3I; Figure 1d) in tissue homogenate from tumors derived after implantation of HepG2 cells in nude mice. The expression of p62 in tumors was not reduced in tumors from sorafenib-treated 
(a)

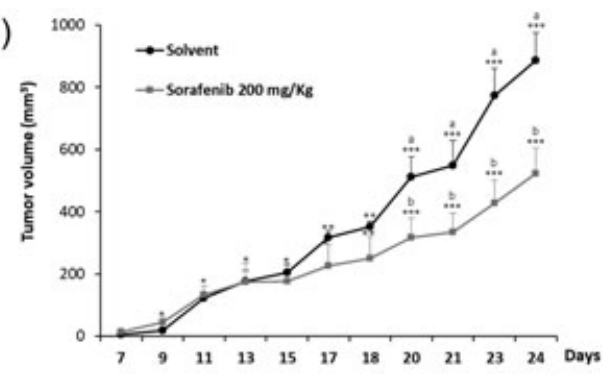

(c)

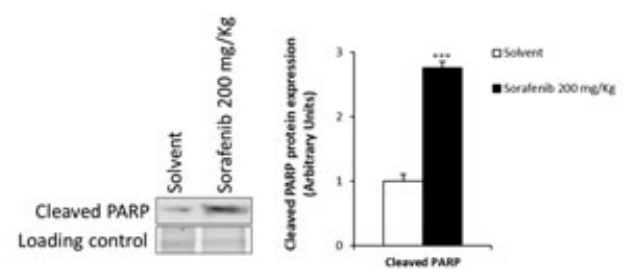

(b)

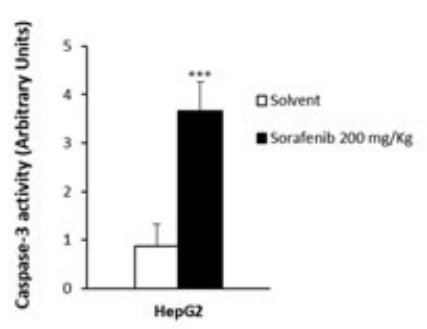

FIGURE 1 Effect of sorafenib on the tumor progression in the xenograft mouse model. HepG2 $\left(10 \times 10^{6}\right)$ were implanted at dorsal level in athymic mice and treatment was initiated when tumor reached $5 \mathrm{~mm}$ using oral administration of sorafenib (200 mg/ $\mathrm{kg})$ or solvent, being killed when one tumor size reached $15 \mathrm{~mm}$ of diameter. Sorafenib reduced tumor size (a), and increased caspase- 3 activity (b), cleaved PARP (c), and autophagy markers (Beclin-1 and LC3II/LC3I) (d) in tumor homogenates. Protein expression was analyzed by western-blot. Results are expressed as mean \pm standard error of the mean, and with the blots are representative of 10 independent experiments. ${ }^{*} p \leq 0.05,{ }^{* *} p \leq 0.01$ and ${ }^{* * *} p \leq 0.001$ between control and sorafenib treatment. The groups with different letters (a or b) were significantly different ( $\left.p \leq 0.05\right)$

animals (Figure 1d). Sorafenib also reduced the volume of tumors derived after implantation of Huh7 and Hep3B in nude mice (Supporting Information Figure S1b). Sorafenib increased apoptosis (TUNEL staining; Supporting Information Figure S1c) and reduced cell proliferation (Ki67; Supporting Information Figure S1d), fibrogenesis ( $\alpha$-SMA; Supporting Information Figure S1e), angiogenesis (CD31; Supplementary Figure S1f) and stemness (CD34; Supporting Information Figure S1g).

\subsection{Sorafenib reduced cell proliferation and increased apoptosis}

Primary human hepatocytes were resistant to the proapoptotic properties of sorafenib (Figure 2a). However, the administration of sorafenib $(10 \mu \mathrm{M})$ increased caspase- 3 in the three HCC cell lines tested at $24 \mathrm{hr}$, with HepG2 being more susceptible than p53-deficient HCC cell lines (Hep3B and Huh7) to the treatment (Figure 2a). Differently, sorafenib moderately reduced cell proliferation in primary hepatocytes, whereas it drastically blocked cell proliferation in HCC cell lines with a half maximal inhibitory concentration $\left(\mathrm{IC}_{50}\right)$ close to $10 \mu \mathrm{M}$ (Figure 2b; $24 \mathrm{hr}$ ).

\subsection{Induction of endoplasmic reticulum stress by sorafenib}

The ER is responsible for the regulation of protein folding and cellular calcium concentrations through three ER transmembrane proteins: PERK, ATF6, and IRE1 (Fribley, Zhang, \& Kaufman, 2009; Szegezdi, Logue, Gorman, \& Samali, 2006). Shi et al. (2011) have reported that sorafenib $(20 \mu \mathrm{M})$ induces ER stress independently of MEK/ERK
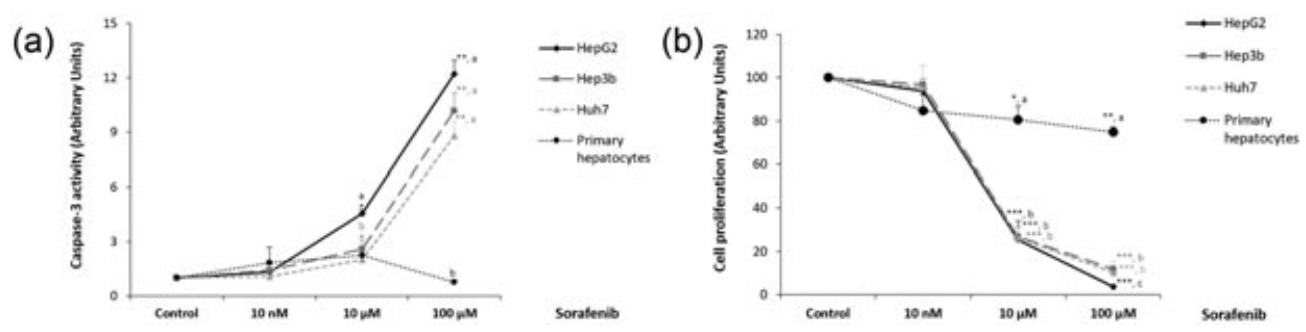

FIGURE 2 Regulation of caspase-3 activity (a) and cell proliferation (b) by sorafenib in HepG2, Hep3b, Huh7, and human primary hepatocytes. Caspase- 3 activity was measured by commercial chemiluminescence-based assay as described in Material and Methods. Cell proliferation was determined by BrdU incorporation as described in Material and Methods. The variables were evaluated $24 \mathrm{hr}$ after sorafenib $(0,10 \mathrm{nM}, 10 \mu \mathrm{M}$, and $100 \mu \mathrm{M})$ administration. Results are expressed as mean \pm standard error of the mean of 3-5 independent experiments. ${ }^{*} p \leq 0.05,{ }^{* *} p \leq 0.01$, and ${ }^{* * *} p \leq 0.001$ between control and sorafenib-treated cells. The groups with different letters (a, b, or $c$ ) were significantly different $(p \leq 0.05)$ 
through PERK and IRE1 pathways that are related to increased apoptosis and autophagy markers respectively in HepG2 and $\mathrm{PLC} / \mathrm{PRF} / 5$. In agreement with these studies, our data showed that sorafenib $(\geq 10 \mu \mathrm{M})$ not only increased the ratio of ${ }^{\text {Ser51 }}{ }^{\mathrm{P}-\mathrm{elF} 2} \alpha / \mathrm{elF} 2 \alpha$ protein expression (Figure $3 \mathrm{a}$ ) and the protein expression of the C/EBP homologous protein (GADD153 or CHOP; Figure 3b) at $6 \mathrm{hr}$, but also that of IRE1 $\alpha$ (Figure $3 \mathrm{c}$ ), and the mRNA expression of XBP1s/XBP1 ratio (Supporting Information Figure S2) at $12 \mathrm{hr}$. Interestingly, we have observed that sorafenib reduced ATF6 protein expression (Figure $3 \mathrm{~d}$ ) at the same range of concentration and time period as increased PERK and IRE1 pathways (Figure $3 a$ and $3 c$, respectively).

\section{4 | Sorafenib decreased ${ }^{\text {Ser2481 }}{ }^{\text {P-mTOR }}$ phosphorylation, impaired initiation of protein synthesis and increased transient autophagy}

The induction of apoptosis by sorafenib has been related to an alteration of protein translation characterized by a reduction of elF4E phosphorylation and Mcl-1 translation, but unassociated with MEK/ERK downregulation in HCC cells (Liu et al., 2006). The mTOR integrates nutrient and mitogen signals to regulate cell growth and cell proliferation. Different pathways have been shown to regulate mTOR signaling by antitumoral agents. The ATF4-mediated increase in the expression of sestrin- 2 caused by nelfinavir- and bortezomib-induced AMPK activity (a)

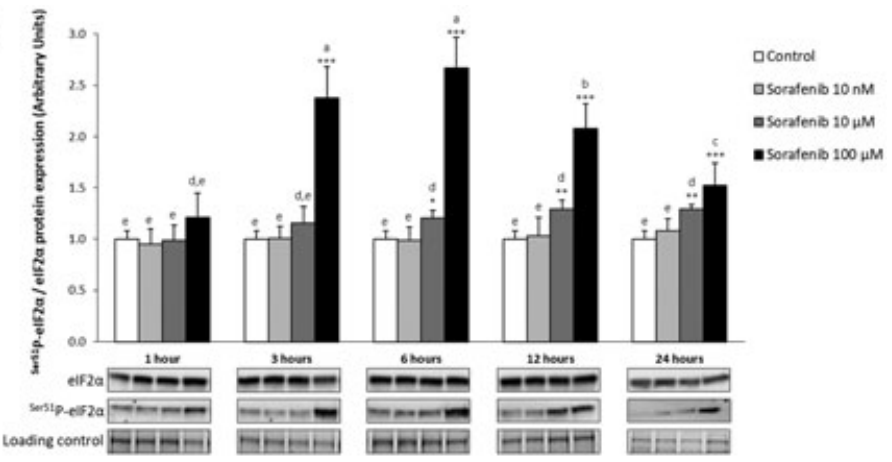

(b)

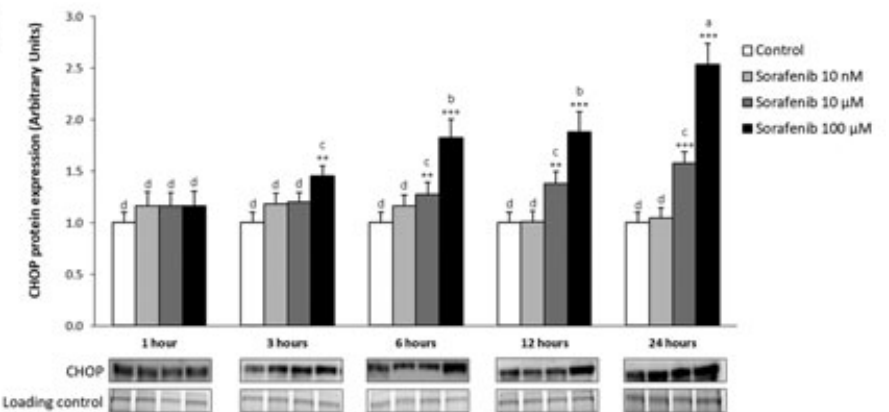

(c)

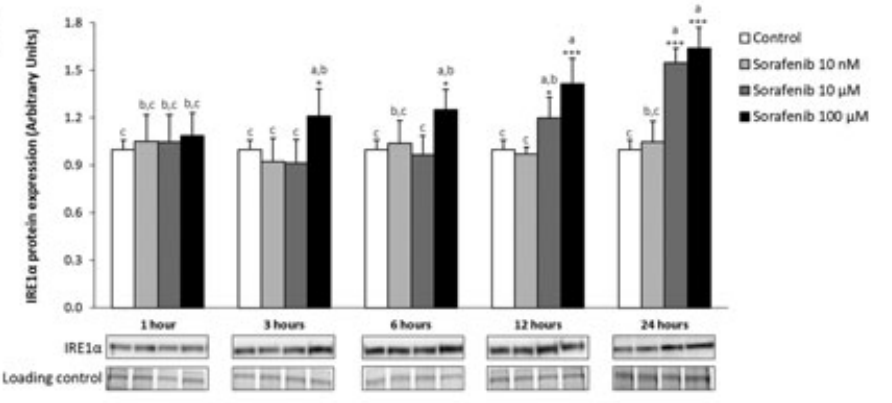

(d)

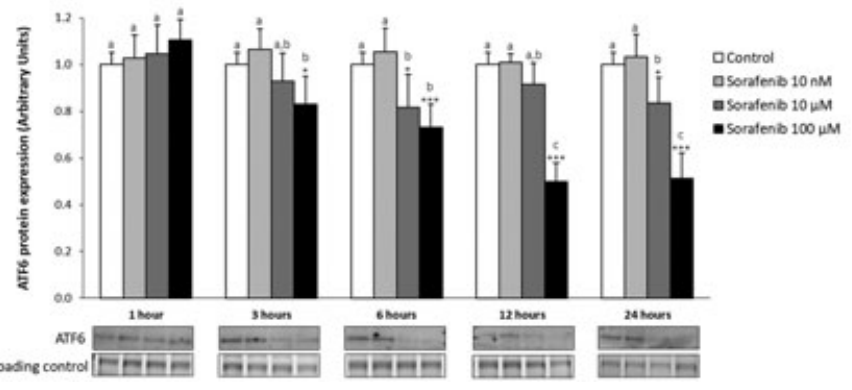

FIGURE 3 Expression of markers from all three branches of ER stress altered by sorafenib in HepG2 cells. A kinetic analysis of the protein expression of Ser51P-elF2 $\alpha /$ eIF2 $\alpha$ (a), CHOP (b), IRE1 $\alpha$ (c) and ATF6 (d) were determined at different sorafenib concentrations $(0,10 \mathrm{nM}, 10 \mu \mathrm{M}$, and $100 \mu \mathrm{M})$ by western-blot analysis as described in Material and Methods. Results are expressed as mean \pm standard error of the mean, and with the blots are representative of five independent experiments. ${ }^{*} p \leq 0.05,{ }^{* *} p \leq 0.01$, and ${ }^{* *} p \leq 0.001$ between control and sorafenib treated cells. The groups with different letters (a, b, c, d, or e) were significantly different $(p \leq 0.05)$. ATF6, activating transcription factor 6; CHOP, C/EBP homologous protein; $E R$, endoplasmic reticulum 
inhibits mTOR and triggers autophagy in breast, ovarian, and cervical cancer cell lines (Brüning, Rahmeh, \& Friese, 2013). Sorafenib promoted an early perturbation of the mitochondrial function, ATP depletion and AMPK-dependent inhibition of the mTORC1 pathway in breast cancer cells (Fumarola et al., 2013). In addition, the sustained activation of phosphatidylinositol 3-Kinase ( $\mathrm{PI} 3 \mathrm{~K}$ )/AKt upregulating mTOR has also been related to sorafenib resistance in HCC cells (Chen et al., 2011). In the current study, we observed that sorafenib $(10 \mu \mathrm{M})$ caused an early and progressive reduction (3-24 hr) of Ser2481 P-mTOR phosphorylation in HepG2 (Figure 4a), as well as in Hep3B and Huh7 cells (Supporting Information Figure S3). Sorafenib $(10 \mu \mathrm{M})$ induced an early upregulation of Thr308 P-AKt phosphorylation (6-12 hr) followed by downregulation of ${ }^{\text {Thr308}} \mathrm{P}$-Akt and ${ }^{\mathrm{Ser} 473} \mathrm{P}-\mathrm{Akt}$ phosphorylation (24-48 hr; Figure $4 \mathrm{~b}$ ). Sorafenib also induced a rapid and transient increase of Thr172P-AMPK phosphorylation (6-12 hr; Figure 4c). Data suggest that mTOR inhibition may be related to the combined signaling of AKt inhibition and AMPK activation.
The inhibition of mTOR by sorafenib has a great impact on protein translation. The polysome profiles in control cells were obtained by observing free $40 \mathrm{~S}$ and $60 \mathrm{~S}$ ribosomal subunits, $80 \mathrm{~S}$ ribosomes, and actively translating polysomes. However, sorafenib $(10 \mu \mathrm{M})$ resulted in abnormal polysome profiles, with a dramatic increase of the 805 peak and a reduction of polysomes (Figure $4 d$ ). Salt treatment dissociated most of the 805 peak into free $40 \mathrm{~S}$ and $60 \mathrm{~S}$ ribosomal subunits, indicating that the large $80 \mathrm{~S}$ ribosome population was mostly nontranslating vacant ribosomes rather than monosomes engaged with mRNA (Supporting Information Figure S4).

The nutrient deprivation, growth factor withdrawal or hypoxia are related to autophagy induction (He \& Klionsky, 2009). The most important pathways involved in autophagy modulation are mTORC1 and AMPK (Prieto-Dominguez et al., 2016). We used the double fluorescent-tagged LC3 (pDest-LC3-GFP-mCherry) plasmid to distinguish autophagosomes from autolysosomes, transmission electronic microscopy (TEM), and biochemical markers to follow (a)

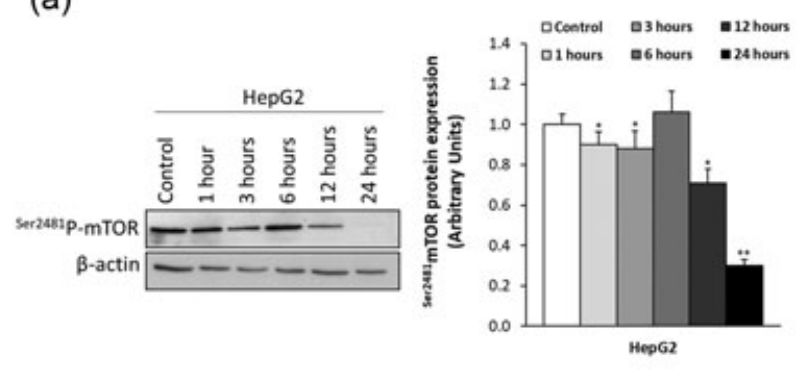

(d)

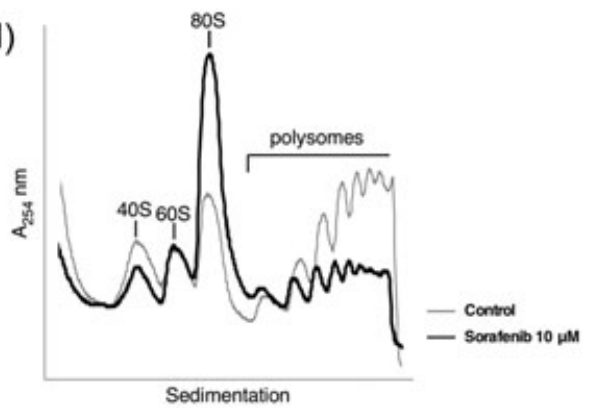

(b)
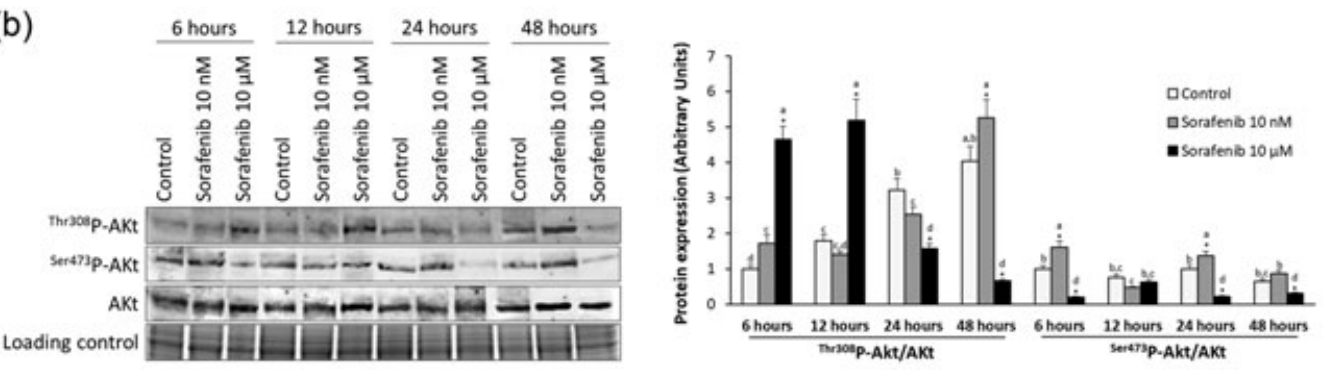

(c)
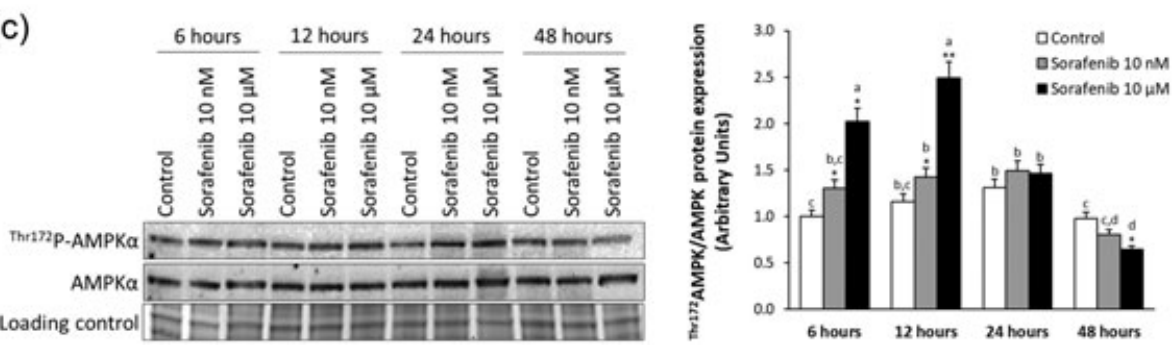

FIGURE 4 Kinetic study of the phosphorylation of mTOR (a), AKt (b), AMPK (c), as well as the alteration in the polysome profile (d) in HepG2 cells treated with sorafenib $(10 \mu \mathrm{M})$. The protein expression was determined by western-blot. Polysome profiles were generated following the procedure described in Material and Methods after $12 \mathrm{hr}$ of sorafenib $(10 \mu \mathrm{M})$ treatment. Results are expressed as mean \pm standard error of the mean, and with the blots are representative of four independent experiments. ${ }^{*} p \leq 0.05,{ }^{* *} p \leq 0.01$ and ${ }^{* * *} p \leq 0.001$ between control and sorafenib-treated cells. The groups with different letters (a, b, $c$, or $d)$ were significantly different $(p \leq 0.05)$. AMPK, $5^{\prime}$ AMP-activated protein kinase; mTOR, mammalian target of rapamycin 
the induction and progression of autophagy flux. We found that sorafenib induced autophagolysosome formation in mRFP-EGFPLC3-transfected cells (Figure 5a), a fact confirmed by TEM imaging (Figure 5b). The quantification of the phagolysosomes (black line) and phagosomes (grey line; Supporting Information Figure S5) and biochemical markers (p62, Beclin-1, and LC3II/I) in HepG2 (Figure 5c) showed that autophagy induced by sorafenib $(10 \mu \mathrm{M})$ was only transiently active (6-12 hr).

\subsection{The inhibition of the ER stress and AMPK downregulated autophagy and increased apoptosis in sorafenib-treated HepG2 cells}

We have evaluated the specific role of ER stress arms and AMPK on autophagy and apoptosis using si-RNA technology and dorsomorphin, respectively. Data showed that IRE $1 \alpha$ and PERK were deeply involved in sorafenib-induced autophagy, whereas a minor effect of ATF6 was also observed ( $6 \mathrm{hr}$; Figure 6a). Thus, the reduction of autophagy by si-IRE $1 \alpha$ and si-PERK increased sorafenib $(10 \mu \mathrm{M})$-induced caspase- 3 activity (Figure $6 \mathrm{~b})$ and PARP cleavage (Figure 6c) in HepG2.

Moreover, the AMPK inhibition by dorsomorphin reduced Thr172P-AMPK/AMPK, Ser413P-Foxo3a/Foxo3a, and Beclin-1 expression induced by sorafenib (Figure $6 \mathrm{~d} ; 12 \mathrm{hr}$ ). However, the sustained reduction of the activating phosphorylation of ${ }^{\text {Thr172 }}{ }^{\mathrm{P}-\mathrm{AMPK} / \mathrm{AMPK}}$ by dorsomorphin was related to a drastic upregulation of Beclin-1 expression (Figure 6d), and downregulation of caspase-3 activity (Figure 6e) and PARP cleavage (Figure 6f) at $24 \mathrm{hr}$ in sorafenibtreated HepG2 cells. In addition, the antiapoptotic properties of autophagy were further confirmed using autophagic inhibitors 3MA and $C Q$ by the upregulation of sorafenib $(10 \mu \mathrm{M})$-induced caspase-3 activity (Figure 6g) and PARP cleavage (Figure 6h) in HepG2 (24 hr).

\subsection{Sorafenib regulated the activation of JNK and Foxo3a, and the expression of proapoptotic, and antiapoptotic Bcl-2 family members}

The $\mathrm{Bcl}-2$ family is a well characterized protein family including antiapoptotic members (Bcl-2, $\mathrm{Mcl}-1$, and $\mathrm{Bcl}-\mathrm{xL}$ ), proapoptotic effectors (Bax and Bak) and proapoptotic $\mathrm{BH}$-only members, which include the BH3-only direct activators Bim, Bid, and Puma (Kim et al., 2006) and the sensitizers/repressors such as Noxa, Bad, Bik, Bmf, and HRK (Willis et al., 2007). The interactions among them, as well as with the autophagic component Beclin-1, result in a potential switch between autophagic and apoptotic cell death pathways. The induction of apoptosis by sorafenib has been related to activation of Bax and Bak, and increased expression of proapoptotic "BH3-domain only" PUMA and BIM, as well as decreased protein levels of the antiapoptotic Mcl-1 (Fernando et al., 2012). The expression of Bim, Bak, Bax, tBid, Bcl-2, Bcl-xL, Beclin-1, and $\mathrm{Mcl}-1$ in sorafenib (10 nM and $10 \mu \mathrm{M})$-treated HepG2 cells is shown in Figure 7a and Supporting Information S6a and S6b. The line chart in Figure $7 \mathrm{~b}$ shows the profile throughout time in the expression of mentioned proteins. Our data suggest that sorafenib $(10 \mu \mathrm{M})$ induced a rapid drop of $\mathrm{Mcl}-1$ protein expression, as well as transient and moderate increase of $\mathrm{tBid}, \mathrm{Bim}_{\mathrm{EL}} \mathrm{BCl}-2$ and $\mathrm{Bcl}-\mathrm{xL}$ (3-6 hr) overlapping with the increase of Beclin-1 (3-12 hr). The expression of tBid drastically dropped below the control value at $6 \mathrm{hr}$, and $\mathrm{Bcl}-2$, $\mathrm{Bcl}-\mathrm{xL}$ and Beclin-1 expressions were reduced at $12 \mathrm{hr}$ after sorafenib treatment (Figure $7 \mathrm{~b}$ ). Among the proapoptotic members, only $\operatorname{Bim}_{\mathrm{EL}}$ showed a sustained increase throughout the kinetic study, reaching the highest value at $24 \mathrm{hr}$ (Figure 7). Bak also showed a moderate rise throughout the study, while Bax expression increased transiently (3-6 hr) returning expression to the control level (Figure 7).

The activation of JNK has been related either to ER-related autophagy (Ogata et al., 2006) or apoptosis (Dhanasekaran \& Reddy, 2008) according to different experimental conditions. The stimulation of ER-induced autophagy by sorafenib showed above was associated with the transient activation of JNK as measured by Thr183, ${ }^{T y r} 185 \mathrm{P}$-JNK1/2/JNK1/2 ratio (3-12 hr; Figure 7c and 7d). The inhibition of the Thr183,Tyr185P-JNK1/2/JNK1/2 ratio was assessed using the specific inhibitor SP600125 (Figure 7d). The treatment reduced cell proliferation in control and sorafenib-treated HepG2 cells (33\% and $41 \%$ at $12 \mathrm{hr}$, and $53 \%$ and $22 \%$ at $24 \mathrm{hr}$, respectively; Figure 7e). In contrast, SP600125 increased caspase- 3 in control and sorafenib-treated HepG2 cells (Figure 7f).

The activation of Foxo and its proapoptotic properties is under regulation of multiple cell signaling (Farhan et al., 2017). The inhibitory phosphorylation ${ }^{\mathrm{Th}} 32 \mathrm{P}$-Foxo3a was transiently upregulated at 6-12 hr, while dropped afterwards in sorafenib $(10 \mu \mathrm{M})$ treated HepG2 cells (Figure 7g).

The role of Bim, Bak, and Bax has also been assessed using si-RNA technology. The reduction of Bim, but not Bak and Bax, by si-RNA recovered caspase- 3 control levels in sorafenib $(10 \mu \mathrm{M})$ treated HepG2 (Figure 8a; $24 \mathrm{hr}$ ). The reduction of apoptosis by si-RNA Bim was associated with upregulation of p62 expression and LC3II/LC3I ratio, but without alteration of Beclin-1 expression in sorafenib-treated HepG2 cells (Figure $8 \mathrm{~b}$ ). The immunoprecipitation experiments showed that Bim, but not Bak and Bax, was able to bind Beclin-1 (Figure 8c).

\section{DISCUSSION}

Sorafenib is, to date, the only approved first-line systemic therapy for patients in advanced stages of HCC. This chemotherapeutic drug has demonstrated a moderate but significant increase of mean overall survival in patients with good liver function based on the results in SHARP and Asia-Pacific clinical trials (7.9 to 10.7 months in Llovet et al., 2008; and from 4.2 to 6.5 months in Cheng et al., 2009; respectively). Beneficial effects have also been reported in patients with thyroid cancer, acute myeloid leukemia, advanced renal cell carcinoma, or prostate cancer (Antar, Kharfan-Dabaja, Mahfouz, \& Bazarbachi, 2015; Chi et al., 2008; Escudier et al., 2007; Luo et al., 2014). Although sorafenib has been effective in extending the overall 
(a)

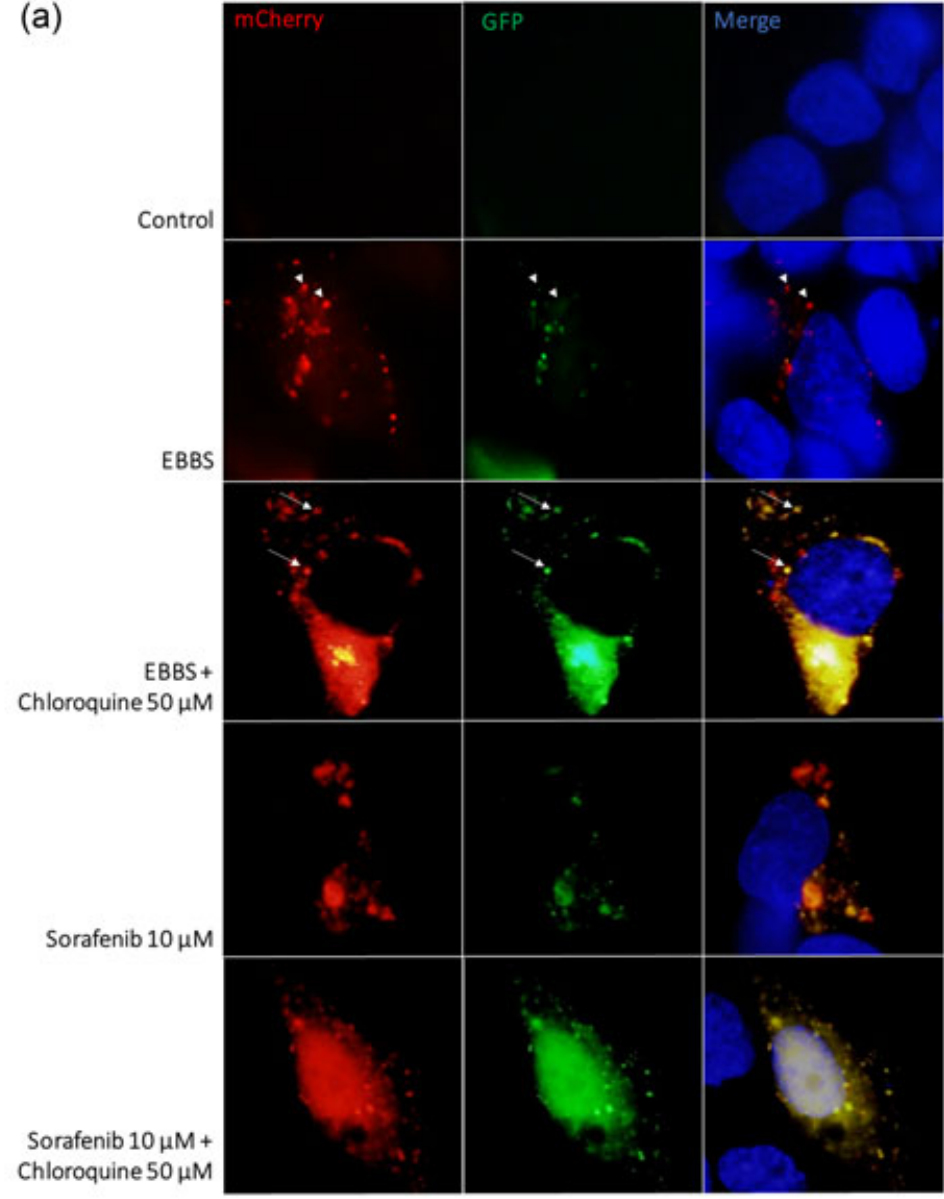

(b)

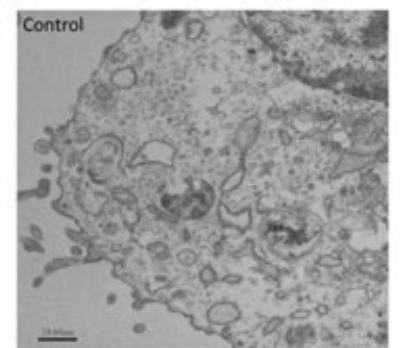

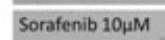

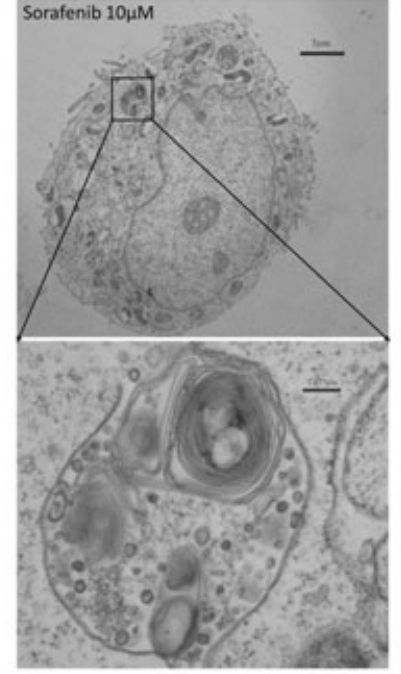

(c)
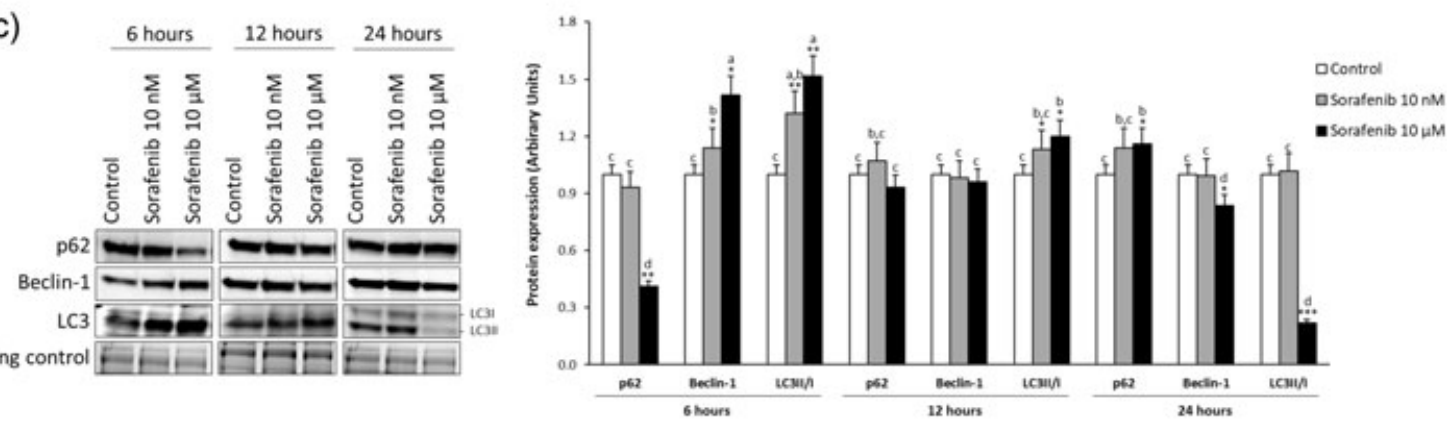

FIGURE 5 Evaluation of autophagic flux (a), presence of autophagolysosomes by electronic transmission microscopy (b) and expression of autophagy markers p62, Beclin-1, and LC3II/I (c) in HepG2 cells treated with sorafenib (10 nM and $10 \mu M)$. The autophagic flux was assessed in HepG2 transfected with double-tagged pDest-LC3-GFP-mCherry plasmid, which is a pH-sensitive sensor to monitor autophagy in live cells ( $6 \mathrm{hr}$ ). The GFP tag is acid-sensitive while the mCherry tag is acid-insensitive. Yellow merge punctate structures indicate autophagosomes which neutral $\mathrm{pH}$ allows both tags emit fluorescent light resulting in a yellow staining. Subsequent fusion of autophagosomes with lysosomes results in red-positive acidic vacuoles where the green fluorescence from GFP is lost. Arrows indicate a typical example of colocalized particles of GFP and mCherry signal, while the arrowhead indicates a typical example of a particle with mCherry signal but without GFP signal due to its degradation. Sorafenib was used at a concentration of $10 \mu \mathrm{M}$, while EBSS was used as positive control treatment and chloroquine (50 $\mu \mathrm{M})$ was used to inhibit autophagic flux. The presence of autophagolysosomes in HepG2 cells treated with sorafenib (10 $\mu$ M) was also detected by transmission electronic microscopy $(12 \mathrm{hr}$ ) following the procedure described in Material and Methods. The protein expression of autophagy markers (p62, Beclin-1, and LC3 II/I) was assessed at 6, 12 and $24 \mathrm{hr}$ in sorafenib (10 nM and $10 \mu \mathrm{M}$ )-treated HepG2 cells by western-blot procedure as described in Material and Methods. Results are expressed as mean \pm standard error of the mean, and with the blots and images are representative of four independent experiments. ${ }^{*} p \leq 0.05,{ }^{* *} p \leq 0.01$, and ${ }^{* * *} p \leq 0.001$ between control and sorafenib-treated cells. The groups with different letters ( $\mathrm{a}, \mathrm{b}, \mathrm{c}$, or $\mathrm{d})$ were significantly different $(p \leq 0.05)$ [Color figure can be viewed at wileyonlinelibrary.com] 
(a)
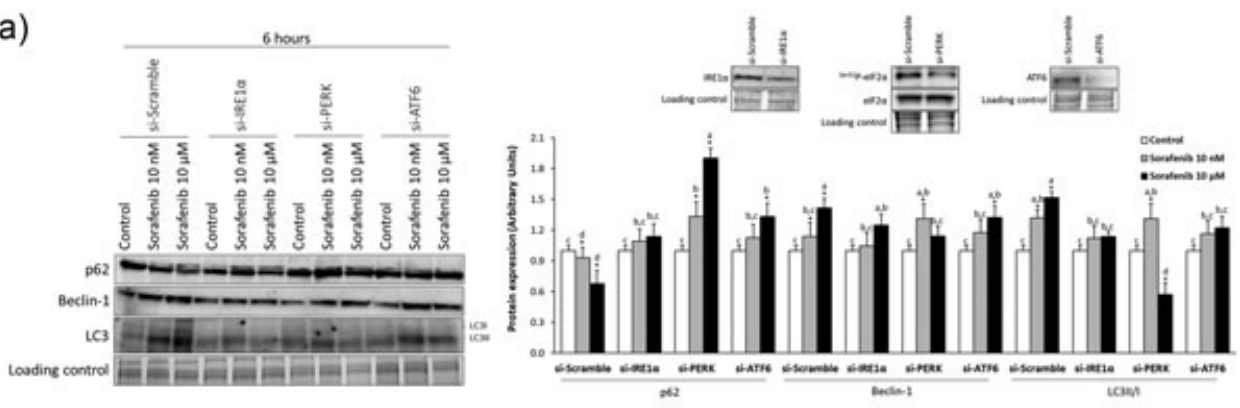

(b)

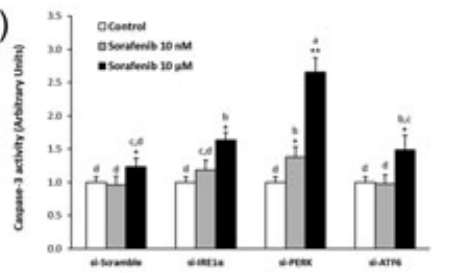

(d)

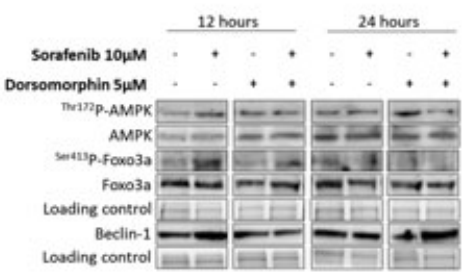

(e)

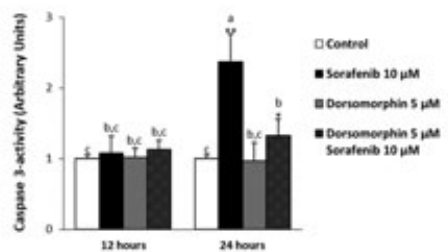

(g)

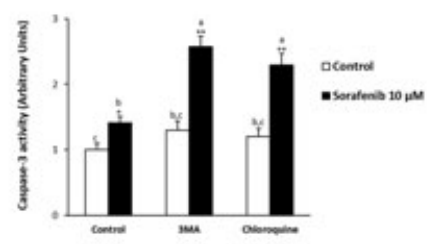

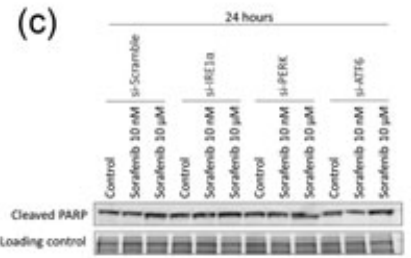
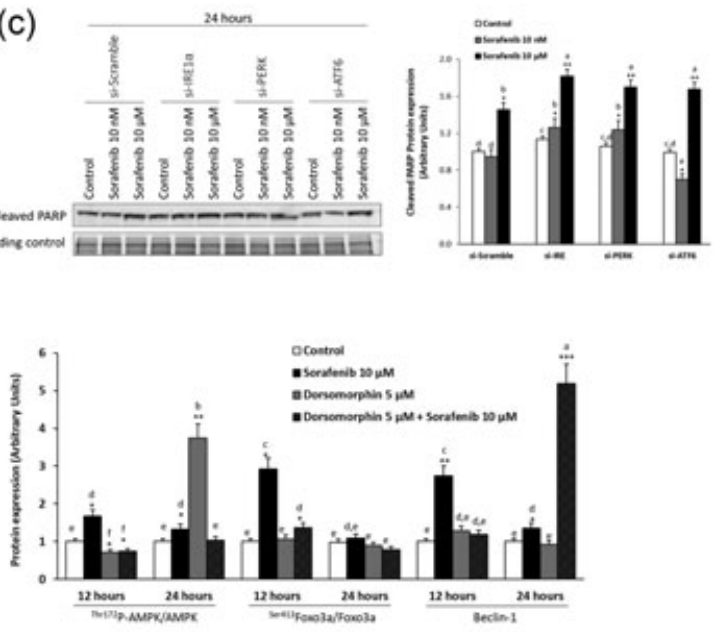

(f)
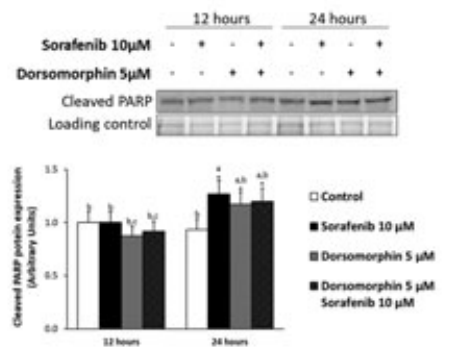

(h)

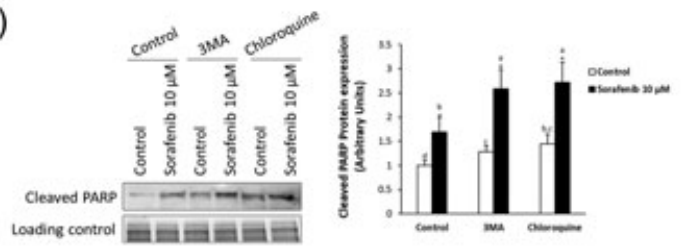

FIGURE 6 Effect of knock-down of ER stress branches, and inhibition of AMPK and autophagy in sorafenib-induced autophagy and apoptosis in HepG2. HepG2 cells were first transfected with IRE1 $\alpha$, PERK, and ATF6 si-RNA duplexes for $48 \mathrm{hr}$ to assess their role in autophagy

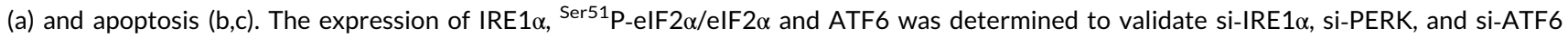
treatments (a). Afterwards, cells were treated for $6 \mathrm{hr}$ with sorafenib $(10 \mathrm{nM}$ and $10 \mu \mathrm{M})$ and harvested for analysis. The inhibition of AMPK was carried out by dorsomorphin $(5 \mu \mathrm{M})$ with or without coadministration with sorafenib $(10 \mu \mathrm{M})$ being measured ${ }^{\text {Thr } 172}$ P-AMPK/AMPK, ${ }^{\mathrm{Ser} 413} \mathrm{FOXO} \mathrm{a} / \mathrm{FOXO} \mathrm{a}$, and Beclin-1 (d) as well as caspase-3 activity (e) and cleaved PARP (f) at 12 and $24 \mathrm{hr}$. The inhibition of autophagy by 3-methyl adenine (3MA; $5 \mu \mathrm{M})$ or chloroquine $(50 \mu \mathrm{M})$ administered $2 \mathrm{hr}$ before sorafenib $(10 \mu \mathrm{M})$ induced caspase-3 activity $(\mathrm{g})$ and cleaved PARP protein expression (h) at $24 \mathrm{hr}$. Autophagy was biochemically followed by the measurement of p62, Beclin-1 and LC3II/I protein expression by western-blot analysis as described in Material and Methods. Apoptosis was analyzed by caspase- 3 activity and cleaved PARP protein expression as described in Material and Methods. Results are expressed as mean \pm standard error of the mean, and with the blots are representative of four independent experiments. ${ }^{*} p \leq 0.05,{ }^{* *} p \leq 0.01$ and ${ }^{* * *} p \leq 0.001$ between Control and sorafenib-treated cells. The groups with different letters (a, b, c, d, e, or f) were significantly different ( $p \leq 0.05)$. AMPK, 5 'AMP-activated protein kinase; ER, endoplasmic reticulum; PERK, pancreatic ER kinase (PKR)-like ER kinase 


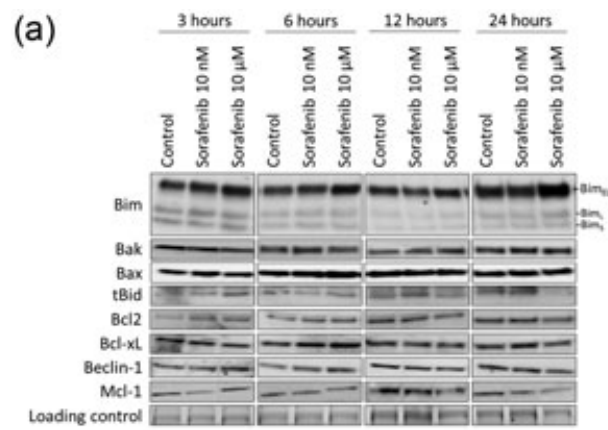

(b)

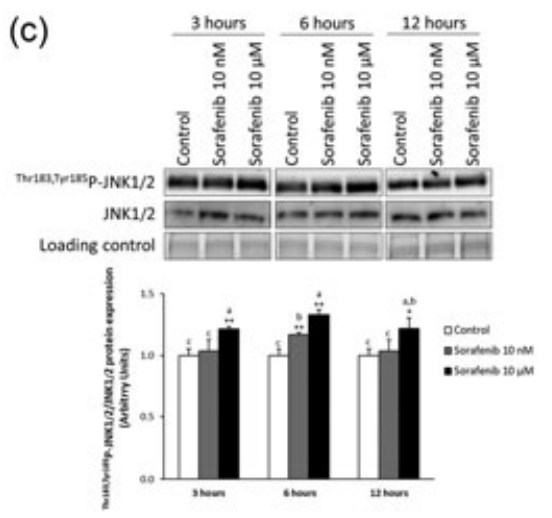

(d)

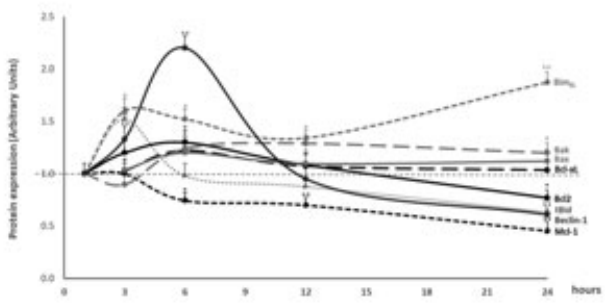

(e)

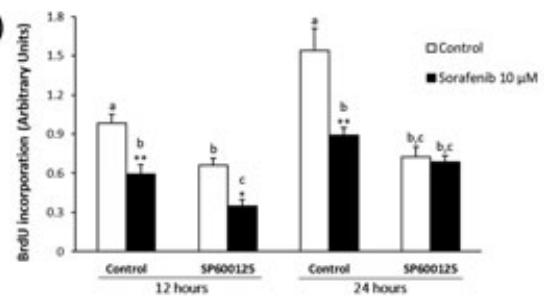

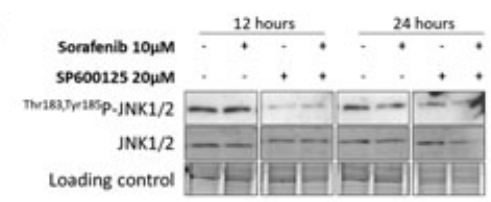

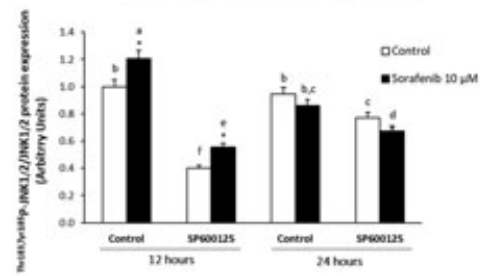

(f)

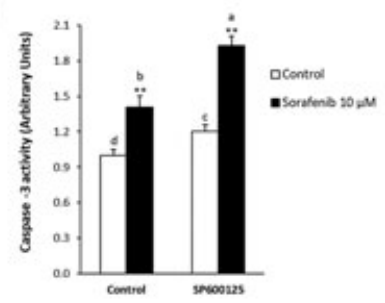

(g)

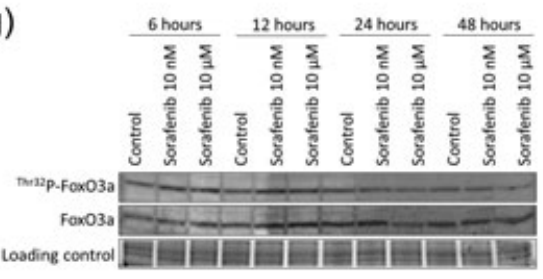

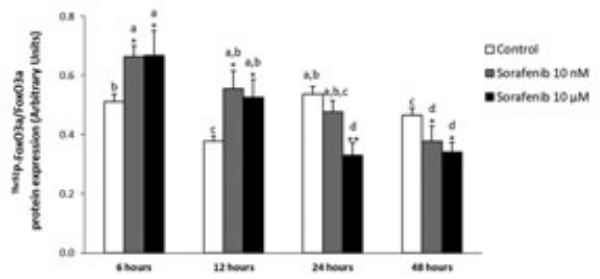

FIGURE 7 Kinetic study of the expression of Bcl-2 family members and Beclin-1 (a,b), JNK phosphorylation (c), and its inhibition on JNK phosphorylation (d), cell proliferation (e) and caspase-3 ( $\mathrm{f}$ ), as well as Foxo3a phosphorylation ( $\mathrm{g}$ ) in sorafenib-treated HepG2 cells. The effect of sorafenib $(10 \mathrm{nM}$ and $10 \mu \mathrm{M})$ on the expression of Bcl-2 family members and Beclin-1 were followed at 3, 6, 12, and $24 \mathrm{hr}$ by western-blot analysis. The effect of

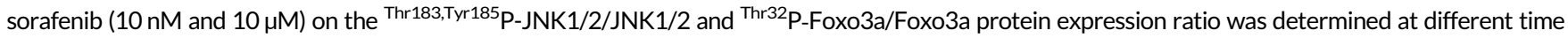
points according to the experiment (3-48 hr). The inhibition of JNK was assessed by the administration of SP600125 (20 $\mu$ M) added to cell culture $12 \mathrm{hr}$ before sorafenib $(10 \mu \mathrm{M})$ treatment. Cell proliferation was determined by BrdU incorporation as described in Material and Methods. Caspase-3 activity was measured by commercial chemiluminescence-based assay as described in Material and Methods. Results are expressed as mean \pm standard error of the mean, and with the blots are representative of four independent experiments. ${ }^{*} p \leq 0.05$ and ${ }^{* *} p \leq 0.01$ between control and sorafenib-treated cells. The groups with different letters (a, b, c, d, e, or f) were significantly different $(p \leq 0.05)$. JNK, c-Jun-N-terminal kinase

survival of patients, only a minor percentage of patients (2\%) displayed partial response to therapy based on response evaluation criteria in solid tumors (RECIST) criteria (Llovet et al., 2008), the low response rate being mainly attributed to intrinsic resistance of $\mathrm{HCC}$ cells to sorafenib (Villanueva \& Llovet, 2012). Several studies have provided mutational profile and identified an average of 30-40 mutations per tumor; among which 5-8 might be driver mutations, as well as high-level amplifications of oncogenes in specific chromosome 

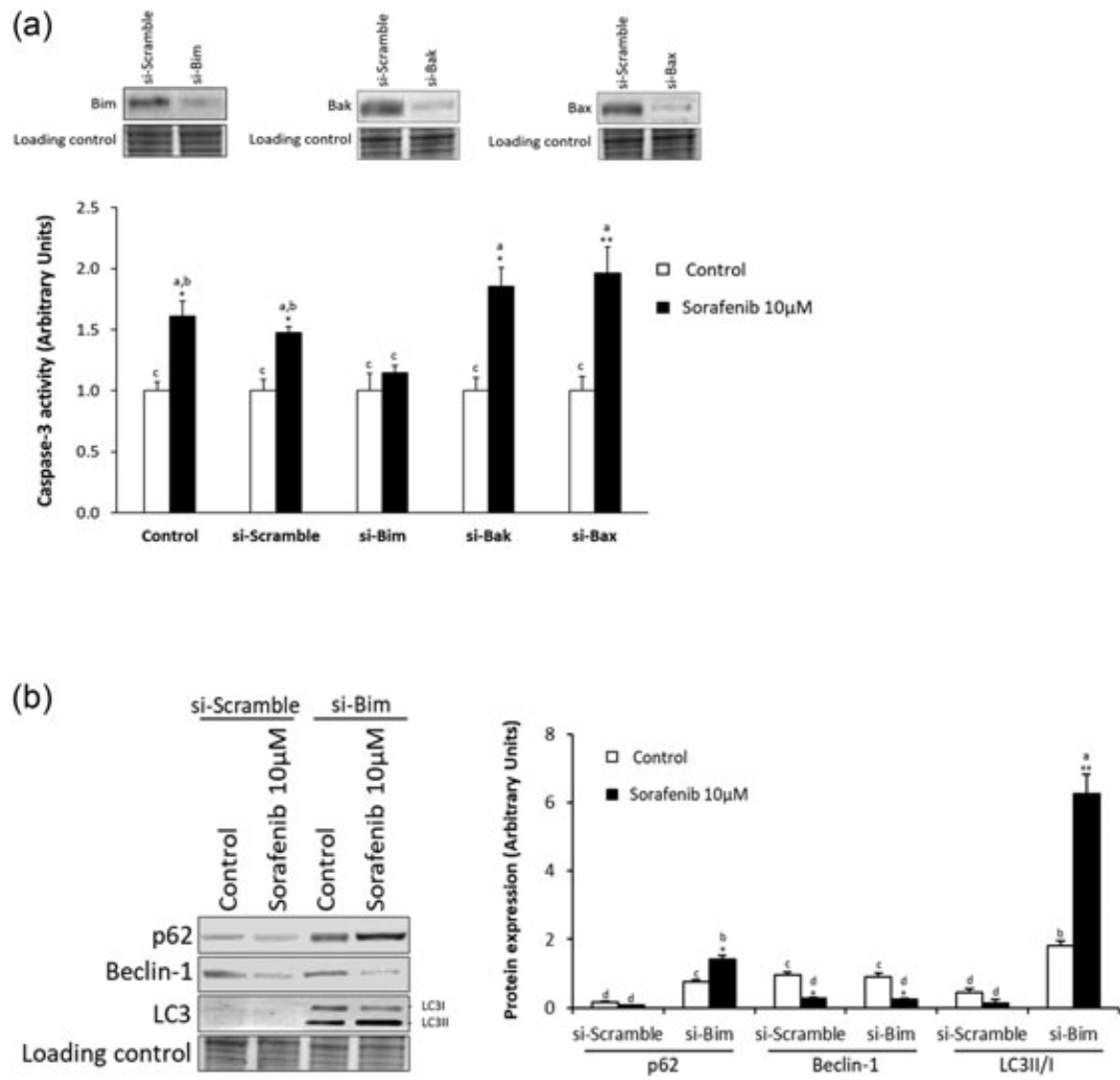

FIGURE 8 Effect of knock-down of Bim, Bak, and Bax on caspase- 3 activity (a) and autophagic markers (p62, Beclin-1, and LC3II/I) (b), as well as the binding capacity of Beclin-1 to Bim, Bak, and Bax (c) in sorafenib-treated HepG2 cells. The expression of Bim, Bak, and Bax was determined to validate si-Bim, si-Bak, and si-Bax treatments (a). The variables were determined at $24 \mathrm{hr}$ after sorafenib $(10 \mu \mathrm{M})$ administration. Caspase-3 activity was measured by commercial chemiluminescence-based assay as described in Material and Methods. The protein expression of autophagy markers and proapoptotic $\mathrm{Bcl}-2$ family members was assessed by western-blot analysis. The immunoprecipitation procedure of Beclin-1

(c)

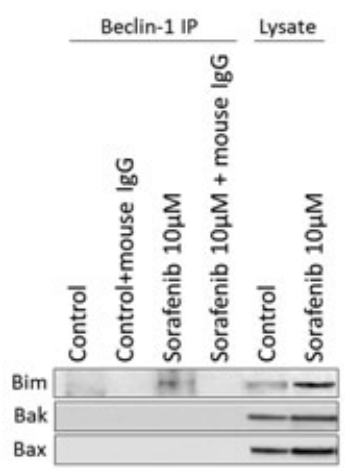

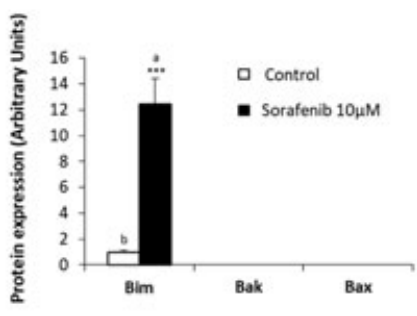
is described in Material and Methods. The immunoprecipitation using unspecific mouse IgG and anti-Beclin-1 antibodies were run in parallel. The expression of Bim, Bak, and Bax has also been measured in the cell lysate. Results are expressed as mean \pm standard error of the mean, and with the blots are representative of eight independent experiments. ${ }^{*} p \leq 0.05$, ${ }^{* *} p \leq 0.01$, and ${ }^{* * *} p \leq 0.001$ between control and sorafenib-treated cells. The groups with different letters ( $a, b, c$, and d) were significantly different $(p \leq 0.05)$ regions. All influence high resistance and reduced extended survival rate during sorafenib treatment in HCC (Llovet, Villanueva, Lachenmayer, \& Finn, 2015).

Sorafenib triggers antiproliferative and antiangiogenic effects through inhibition of the activity of several tyrosine kinase receptors including VEGFR-2/3, PDGFR- $\beta$, Flt3, and c-Kit, nonreceptor tyrosine kinase receptors such as Flt3, as well as Raf serine/threonine kinase (Cervello et al., 2012; Wilhelm et al., 2004). Antiproliferative and antiangiogenic effects induced by sorafenib, both in vitro and in vivo conditions, are driven through different mechanisms and promote apoptosis via both the extrinsic and the intrinsic pathway in HCC cells (Fernando et al., 2012). The in vivo administration of sorafenib $(200 \mathrm{mg} / \mathrm{kg}$ ) reduced tumor growth characterized by reduction of cell proliferation (ki67) and promoted apoptosis (caspase-3, cleaved PARP, and TUNEL) in tumors developed from subcutaneously HCC implanted cells in nude mice (Figure 1 and Supporting Information Figure S1). Sorafenib also increased Beclin-1 and LC3II/LC3I, but did not reduce the p62 expression in tissue homogenate, which may reflect high autophagic turnover in coexistence with apoptotic processes (Figure 1d). The effectiveness of sorafenib is probably a result of a balance between targeting cancer cells and the microenvironment (Llovet et al., 2015). In this sense, it is interesting to notice that the administration of sorafenib reduced fibrogenesis $(\alpha-S M A)$, angiogenesis (CD31), and the presence of hematopoietic stem cells (CD34) in tumors (Supporting Information Figure S1). These results, as well as those related to the antiproliferative 
properties of the drug, are mostly dependent on the inhibition of tyrosine kinase receptors and the Raf/MEK/ERK.

The mechanism by which sorafenib induces apoptosis is not fully elucidated, and the effectiveness and adverse events are related to the dose used. The mean trough sorafenib concentration is $4.3 \pm 2.5 \mathrm{mg} / \mathrm{L}$ in cancer patients under sorafenib monotherapy with the recommended dose ( $400 \mathrm{mg}, 12 \mathrm{hr}$ ), which are increased up to $7.7 \pm 3.6 \mathrm{mg} / \mathrm{L}$ in patients who experienced grade 3 drug-related adverse events (Blanchet et al., 2009). The corresponding therapeutic concentration of sorafenib used in the study is $10 \mu \mathrm{M}$. It has been associated with the inhibition of phosphorylation of the initiation factor elF4E and loss of the antiapoptotic Bcl-2 family members Mcl-1 which appear to occur through a MEK/ERK independent mechanism in different cancer cell lines treated with sorafenib (Rahmani, Davis, Bauer, Dent, \& Grant, 2005; Yu et al., 2005). Mcl-1, an antiapoptotic member of the Bcl-2 family, has been shown to be an important factor for apoptosis resistance in HCC (Fleischer et al., 2006). Sorafenib $(10 \mu \mathrm{M})$ reduced the level of P-elF4E and Mcl-1 at 2 and $16 \mathrm{hr}$ after treatment in HepG2 and PLC/PRF/5 cells (Liu et al., 2006). However, we found that there is no temporal relationship between $\mathrm{Mcl}-1$ downregulation and induction of apoptosis by sorafenib in HCC cells. In our conditions, caspase- 3 activity was significantly increased $24 \mathrm{hr}$ after the administration of sorafenib $(10 \mu \mathrm{M})$ in HepG2 cells. HCC cells with mutated p53 (Huh7) and nonsense p53 mutation (Hep3B) required high sorafenib concentration $(100 \mu \mathrm{M})$ to induce caspase-3 activation (Figure 2a). Data showed that the antiproliferative and proapoptotic kinetics induced by the drug were more potent in HCC cell lines than in primary human hepatocytes (Figure 2). In this sense, primary human hepatocytes were resistant to the proapoptotic properties of sorafenib treatment (Figure 2a). This aspect is relevant for the specificity of sorafenib for liver cancer cells instead of healthy hepatocytes. We undertook experiments to identify the differential pattern of miRNA expression upon sorafenib treatment among primary human hepatocytes and cancer cells.

One well-characterized function of mTORC1 is to maintain protein synthesis through phosphorylation of at least two direct targets, eukaryotic initiation factor (elF) 4E-binding proteins (4E-BPs) and ribosomal protein S6 kinases (S6Ks) (Hay \& Sonenberg, 2004). mTOR is regulated by different cell signaling involving ER stress, AKt, and AMPK (Rashid, Yadav, Kim, \& Chae, 2015). The induction of PERK signaling by antitumoral drugs inhibits mTOR and triggers autophagy in different cancer cell lines (Bruning et al., 2013). Sorafenib $(10 \mu \mathrm{M})$ significantly increased PERK- and IRE1 $\alpha$-related signaling at $6 \mathrm{hr}$ in HepG2 cells (Figure 3). The significant reduction of ATF6 (Figure 3d) may be related to the alteration of trafficking between the ER and the Golgi apparatus, as well as the overall secretory pathway induced by sorafenib ( $\mathrm{Yi}$ et al., 2012). The activation of PERK and IRE1 $\alpha$ signaling

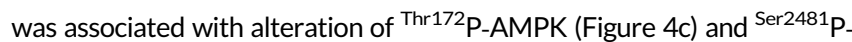
mTOR (Figure 4a). In addition, the early downregulation of mTOR activation appeared not to be related to reduced AKt phosphorylation.

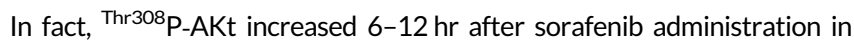
HepG2 (Figure 4b). The activation of survival pathways on mTOR inhibition has been associated with upregulation of IGF-I receptor in breast (O'Reilly et al., 2006) and rhabdomyosarcoma (Wan, Harkavy, Shen, Grohar, \& Helman, 2007) cell lines. The inhibition of the mTOR pathway is in agreement with the drastic alteration of polysome profile we observed in sorafenib-treated HepG2 cells. In agreement with Sauzay et al. (2018), sorafenib induced a blockage of translation at initial stage (Figure 4d and Supporting Information Figure 4).

The most important pathways involved in autophagy modulation are mTORC1 and AMPK (Prieto-Dominguez et al., 2016). The inhibition of mTOR by sorafenib appeared to be stronger in HepG2 (Figure 4a) than in Hep3B and Huh7 (Supporting Information Figure S3). However, the activation of autophagic process using the tandem pDest-LC3-GFPmCherry plasmid transfected to sorafenib-treated cells (Figure 5a), TEM (Figure 5b) and biochemical markers (Figure 5c) were more closely correlated to the activation of ER stress (Figure 3) and AMPK (Figure 4c) than mTOR inhibition (Figure 4a). The respective use of si-RNA and inhibitory compounds showed that ER stress (Figure 6a) and AMPK activation (Figure 6d) played an essential role during sorafenibinduced autophagy in HepG2. The inhibition of autophagy by si-IRE1 $\alpha$ and si-PERK, as well as 3MA, and CQ increased caspase-3 (Figure $6 \mathrm{~b}$ and $6 \mathrm{~g}$, respectively) and PARP cleavage (Figure $6 \mathrm{c}$ and $6 \mathrm{~h}$, respectively). It was also interesting to notice that the downregulation of autophagy by reduction of ${ }^{\text {Thr172}} \mathrm{P}$-AMPK/AMPK ratio using dorsomorphin observed at $12 \mathrm{hr}$ was followed by a drastic upregulation of Beclin-1 (Figure 6d) and reduction of caspase-3 activity (Figure 6e) and PARP cleavage (Figure 6f) in sorafenib-treated HepG2 cells at $24 \mathrm{hr}$. The experiments confirmed Thr172P-AMPK/AMPK ratio was positively correlated to the

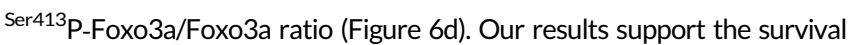
properties of autophagy, and it may suggest an autophagic alternative activation pathway in dorsomorphin and sorafenib cotreated HepG2 cells.

Urano et al. (2000) reported that ER stress and, in particular the IRE1 kinase activity, increases JNK activity. The autophagic process, as apoptosis, appeared to be tightly regulated by anti- and proapoptotic members of the Bcl-2 family. The activation of the autophagic process (6$12 \mathrm{hr}$ ) by sorafenib was associated with a drastic increase of Beclin-1 expression, which it was preceded by rapid downregulation of Mcl-1 and upregulation of $\mathrm{tBid}$ and $\mathrm{Bim}_{\mathrm{EL}}$, while $\mathrm{BCl}-2$ and $\mathrm{Bcl}-\mathrm{xL}$ remained at moderate levels during this period after drug administration (Figure $7 \mathrm{a}$ and 7b, and Supporting Information Figure S6). Interestingly, tBid and Bim $_{\mathrm{EL}}$ have been shown to promote autophagy by displacing Beclin-1 from its interaction with Bcl-2 (Erlich et al., 2007; Marquez \& Xu, 2012). In fact, Beclin-1 has been identified as a BH3-only protein (Maiuri et al., 2007) that allows its interaction with $\mathrm{Bcl} 2$ and its homologue $\mathrm{Bcl}-\mathrm{xL}$ (Oberstein, Jeffrey, \& Shi, 2007). The expression of Beclin-1 (Park et al., 2009) and Bcl-2 phosphorylation that disrupts Beclin-1-Bcl-2 complex-1 (Wei, Pattingre, Sinha, Bassik, \& Levine, 2008) have been related to the

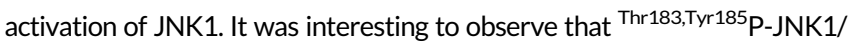
2/JNK1/2 was induced by sorafenib $(10 \mu \mathrm{M})$ during the period in which autophagy was activated (3-12 hr; Figure 7c). The inhibition of Thr183, Tyr185P-JNK1/2/JNK1/2 (Figure 7d) by SP600125 was related to a reduction in cell proliferation (Figure 7e) that resulted in an increased apoptosis (Figure 7f), suggesting that JNK played a survival role during 


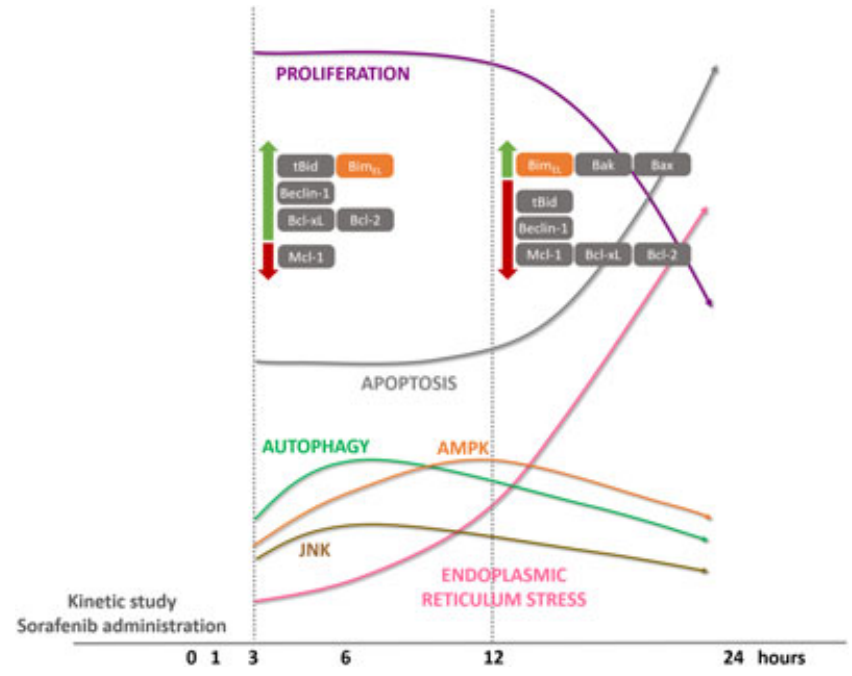

FIGURE 9 The early sorafenib-induced ER stress and the regulation of JNK and AMPK-dependent signaling were related to the induction of the survival autophagic process. The shift from autophagy to apoptosis was related to the decline of tBid, Beclin-1, $\mathrm{Mcl}-1, \mathrm{Bcl}-\mathrm{xL}$, and $\mathrm{Bcl}-2$, as well as the increase of proapoptotic BimEL, Bak, and Bax. BimEL appeared to be critical for the induction of apoptosis by sorafenib. AMPK, 5'AMP-activated protein kinase; $\mathrm{ER}$, endoplasmic reticulum; JNK, c-Jun-N-terminal kinase [Color figure can be viewed at wileyonlinelibrary.com]

sorafenib-induced apoptosis. In addition, a timeframe relationship existed between JNK and AMPK activation, supporting the existence of a complex signaling module involving LKB1, AMPK and JNK, in which early phase of JNK activation was also promoting cell survival by inducing AMPK activity, whereas the late phase of JNK activation induced apoptosis (Yun et al., 2009).

The activation of apoptosis by sorafenib was coincident with a sustained increase in Bim $_{E L}$ expression, remaining Bak and Bax at a moderate expression level (Figure $7 \mathrm{a}$ and $7 \mathrm{~b}$, and Supporting Information Figure S6). JNK has also been observed to induce phosphorylation of Bim, promoting its release from its binding to dynein and myosin $\mathrm{V}$ motor complexes (Lei \& Davis, 2003). Sorafenib $(10 \mu M)$ induced a sustained and progressive increase of CHOP expression (6-24 hr; Figure 3b). The main effector of PERK-mediated apoptosis is the proapoptotic transcription factor CHOP which can be induced by ATF4, ATF6, as well as XBP1s (Verfaillie, Salazar, Velasco, \& Agostinis, 2010). Interestingly, CHOP suppresses the expression of the antiapoptotic Bcl-2 (McCullough, Martindale, Klotz, Aw, \& Holbrook, 2001) and promotes the transcription of the proapoptotic BH3-only protein Bim (Puthalakath et al., 2007). The induction of thapsigargin-induced ER has also been related to a stabilization of Bim by PP2A-related dephosphorylation that prevents its ubiquitination and degradation, as well as by transcriptional regulation though CHOP-ATF4 in breast cancer cells (Puthalakath et al., 2007). The expression of Bim is also under positive transcriptional regulation of Foxo3a (Nakamura \& Sakamoto, 2008) whose activity is regulated by a plethora of kinases such as GSK3 $\beta$, MST1, JNK, CS1, AMPK, and AKt (Farhan et al., 2017). As described above, a positive correlation appeared between ${ }^{\text {Thr } 172}$ P-AMPK/AMPK ratio and related activation phosphorylation of ${ }^{\mathrm{Ser} 413} \mathrm{P}$-Foxo3a/Foxo3a ratio (Figure 6d). In addition, $\mathrm{PISK} / \mathrm{AKt}$ survival signaling increases the inhibitory phosphorylation

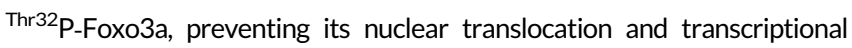
activity (Brunet et al., 1999). Our study also showed that the expression of Bim $_{\mathrm{EL}}$ raised shortly after sorafenib administration which was maintained at moderate expression levels during autophagic-related phase (6-12 hr). This expression level might be the result of the interaction between the upregulation of ${ }^{T h}{ }^{308} \mathrm{P}$-AKt (Figure 4b)dependent Thr32P-Foxo3a (Figure 7g), and Thr172P-AMPK (Figure 4c)dependent Ser413P-Foxo3a (Figure 6d) in sorafenib-treated HepG2. Additional studies should be undertaken to identify the relevance of each pathway in the expression of Bim $\mathrm{ELL}_{\mathrm{EL}}$. The sustained increase of PERK and $\mathrm{CHOP}$ expressions (Figure $3 \mathrm{a}$ and $3 \mathrm{~b}$, respectively) and reduction of AKt phosphorylation ( $24 \mathrm{hr}$; Figure $4 \mathrm{~b}$ ) supports $\mathrm{Bim}_{\mathrm{EL}}$ upregulation during sorafenib-induced apoptotic phase $(24 \mathrm{hr})$ in HepG2. The administration of Bim si-RNA, but not Bak or Bax, prevented sorafenibinduced caspase-3 activity in HepG2 cells (Figure 8a). The reduction of apoptosis by Bim si-RNA was associated with upregulation of $\mathrm{p} 62$ expression and LC3II/LC3I ratio, but without alteration of Beclin-1 expression in sorafenib-treated HepG2 cells (Figure 8b). The proapoptotic BH3-only members such as Bim EL and others like BNIP3, Bad, Bik, Puma, and Noxa, induce autophagy by disrupting the Beclin-1-Bcl2 complex (Marquez \& Xu, 2012). The immunoprecipitation studies demonstrated the formation of Beclin-1 and Bim complex (Figure 8c). In this sense, our study may also suggest that the absence of Bim by si-RNA promotes the induction of early autophagic structures by sorafenib $(10 \mu \mathrm{M})$ independently of Beclin-1 expression which remain at low level at $24 \mathrm{hr}$ (Figure 8b).

In conclusion, our study showed that the induction of ER stress by sorafenib was the driving mechanism involved in the sequential induction of autophagy and apoptosis in HepG2 cells (Figure 9). The early sorafenib-induced ER stress and regulation of JNK and AMPKdependent signaling were related to the induction of survival autophagic process (3-12 hr). The sustained treatment with sorafenib induced a progressive increase of ER stress and PERK-CHOPdependent rise of $\mathrm{Bim}_{\mathrm{EL}}$, which induced the shift from autophagy to apoptosis ( $24 \mathrm{hr}$ ). However, the kinetic of BimeL expression profile might also be related to the tight balance between AKt- and AMPKrelated signaling in Foxo3a-dependent Bim $_{\mathrm{EL}}$ upregulation.

\section{ACKNOWLEDGMENTS}

We thank CIBEREHD and CIBERNED, founded by the ISCIII and cofinanced by European Development Regional Fund "A way to achieve Europe" ERDF, for their financial support. The tandem fusion pDest-LC3GFP-mCherry was kindly provided by Dr. Terje Johansen (Molecular Cancer Research Group, Department of Medical Biology, University of Tromsø-The Arctic University of Norway, Tromsø, Norway).

\section{CONFLICTS OF INTEREST}

The authors have no commercial associations that might create a conflict of interest in connection with the present submitted 
manuscripts. The authors declare there are any competing financial interests in relation to the work described.

\section{ORCID}

Jordi Muntané (D) http://orcid.org/0000-0002-6744-1121

\section{REFERENCES}

Antar, A., Kharfan-Dabaja, M. A., Mahfouz, R., \& Bazarbachi, A. (2015) Sorafenib maintenance appears safe and improves clinical outcomes in FLT3-ITD acute myeloid leukemia after allogeneic hematopoietic cell transplantation. Clinical Lymphoma, Myeloma \& Leukemia, 15(5), 298-302.

Blanchet, B., Billemont, B., Cramard, J., Benichou, A. S., Chhun, S., Harcouet, L., ... Tod, M. (2009). Validation of an HPLC-UV method for sorafenib determination in human plasma and application to cancer patients in routine clinical practice. Journal of Pharmaceutical and Biomedical Analysis, 49(4), 1109-1114.

Bruix, J., Reig, M., \& Sherman, M. (2016). Evidence-based diagnosis, staging, and treatment of patients with hepatocellular carcinoma. Gastroenterology, 150(4), 835-853.

Brunet, A., Bonni, A., Zigmond, M. J., Lin, M. Z., Juo, P., Hu, L. S., ... Greenberg, M. E. (1999). Akt promotes cell survival by phosphorylating and inhibiting a Forkhead transcription factor. Cell, 96(6), 857-868.

Brüning, A., Rahmeh, M., \& Friese, K. (2013). Nelfinavir and bortezomib inhibit mTOR activity via ATF4-mediated sestrin-2 regulation. Molecular Oncology, 7(6), 1012-1018.

Cervello, M., Bachvarov, D., Lampiasi, N., Cusimano, A., Azzolina, A., McCubrey, J. A., \& Montalto, G. (2012). Molecular mechanisms of sorafenib action in liver cancer cells. Cell Cycle, 11(15), 2843-2855.

Colella, A. D., Chegenii, N., Tea, M. N., Gibbins, I. L., Williams, K. A., \& Chataway, T. K. (2012). Comparison of stain-free gels with traditional immunoblot loading control methodology. Analytical Biochemistry, 430 (2), 108-110.

Chen, K. F., Chen, H. L., Tai, W. T., Feng, W. C., Hsu, C. H., Chen, P. J., \& Cheng, A. L. (2011). Activation of phosphatidylinositol 3-kinase/Akt signaling pathway mediates acquired resistance to sorafenib in hepatocellular carcinoma cells. Journal of Pharmacology and Experimental Therapeutics, 337(1), 155-161.

Chen, K. F., Tai, W. T., Liu, T. H., Huang, H. P., Lin, Y. C., Shiau, C. W., ... Cheng, A. L. (2010). Sorafenib overcomes TRAIL resistance of hepatocellular carcinoma cells through the inhibition of STAT3. Clinical Cancer Research, 16(21), 5189-5199.

Cheng, A. L., Kang, Y. K., Chen, Z., Tsao, C. J., Qin, S., Kim, J. S., ... Guan, Z. (2009). Efficacy and safety of sorafenib in patients in the Asia-Pacific region with advanced hepatocellular carcinoma: A phase III randomised, double-blind, placebo-controlled trial. The Lancet Oncology, 10 (1), 25-34.

Chi, K. N., Ellard, S. L., Hotte, S. J., Czaykowski, P., Moore, M., Ruether, J. D., ... Seymour, L. (2008). A phase II study of sorafenib in patients with chemo-naive castration-resistant prostate cancer. Annals of Oncology, 19(4), 746-751.

Dhanasekaran, D. N., \& Reddy, E. P. (2008). JNK signaling in apoptosis. Oncogene, 27(48), 6245-6251.

Erlich, S., Mizrachy, L., Segev, O., Lindenboim, L., Zmira, O., Adi-Harel, S., ... Pinkas-Kramarski, R. (2007). Differential interactions between Beclin 1 and Bcl-2 family members. Autophagy, 3(6), 561-568.

Escudier, B., Eisen, T., Stadler, W. M., Szczylik, C., Oudard, S., Siebels, M., ... Bukowski, R. M., Group TS. (2007). Sorafenib in advanced clear-cell renal-cell carcinoma. The New England Journal of Medicine, 356(2), 125-134.
Farhan, M., Wang, H., Gaur, U., Little, P. J., Xu, J., \& Zheng, W. (2017). FOXO signaling pathways as therapeutic targets in cancer. International Journal of Biological Sciences, 13(7), 815-827.

Fattovich, G., Stroffolini, T., Zagni, I., \& Donato, F. (2004). Hepatocellular carcinoma in cirrhosis: Incidence and risk factors. Gastroenterology, 127(5 Suppl 1), S35-S50.

Fernando, J., Sancho, P., Fernández-Rodriguez, C. M., Lledó, J. L., Caja, L., Campbell, J. S., ... Fabregat, I. (2012). Sorafenib sensitizes hepatocellular carcinoma cells to physiological apoptotic stimuli. Journal of Cellular Physiology, 227(4), 1319-1325.

Fischer, T. D., Wang, J. H., Vlada, A., Kim, J. S., \& Behrns, K. E. (2014). Role of autophagy in differential sensitivity of hepatocarcinoma cells to sorafenib. World Journal of Hepatology, 6(10), 752-758.

Fleischer, B., Schulze-Bergkamen, H., Schuchmann, M., Weber, A., Biesterfeld, S., Müller, M., ... Galle, P. (2006). Mcl-1 is an antiapoptotic factor for human hepatocellular carcinoma. International Journal of Oncology, 28(1), 25-32.

Fribley, A., Zhang, K., \& Kaufman, R. J. (2009). Regulation of apoptosis by the unfolded protein response. Methods in Molecular Biology, 559, 191-204.

Fumarola, C., Caffarra, C., La Monica, S., Galetti, M., Alfieri, R. R., Cavazzoni, A., ... Bonelli, M. A. (2013). Effects of sorafenib on energy metabolism in breast cancer cells: Role of AMPK-mTORC1 signaling. Breast Cancer Research and Treatment, 141(1), 67-78.

Hay, N., \& Sonenberg, N. (2004). Upstream and downstream of mTOR. Genes \& Development, 18(16), 1926-1945.

He, C., \& Klionsky, D. J. (2009). Regulation mechanisms and signaling pathways of autophagy. Annual Review of Genetics, 43, 67-93.

Huynh, H., Ngo, V. C., Koong, H. N., Poon, D., Choo, S. P., Thng, C. H., ... Soo, K. C. (2009). Sorafenib and rapamycin induce growth suppression in mouse models of hepatocellular carcinoma. Journal of Cellular and Molecular Medicine, 13(8B), 2673-2683.

Kim, H., Rafiuddin-Shah, M., Tu, H. -C., Jeffers, J. R., Zambetti, G. P., Hsieh, J. J. D., \& Cheng, E. H. Y. (2006). Hierarchical regulation of mitochondrion-dependent apoptosis by BCL-2 subfamilies. Nature Cell Biology, 8(12), 1348-1358.

Kressler, D., de la Cruz, J., Rojo, M., \& Linder, P. (1997). Fal1p is an essential DEAD-box protein involved in 40S-ribosomal-subunit biogenesis in Saccharomyces cerevisiae. Molecular and Cellular Biology, 17(12), 7283-7294.

Lei, K., \& Davis, R. J. (2003). JNK phosphorylation of Bim-related members of the Bcl2 family induces Bax-dependent apoptosis. Proceedings of the National Academy of Sciences of the United States of America, 100(5), 2432-2437.

Liu, L., Cao, Y., Chen, C., Zhang, X., McNabola, A., Wilkie, D., ... Carter, C. (2006). Sorafenib blocks the RAF/MEK/ERK pathway, inhibits tumor angiogenesis, and induces tumor cell apoptosis in hepatocellular carcinoma model PLC/PRF/5. Cancer Research, 66(24), 11851-11858.

Luo, Y., Shi, Y., Xing, P., Wang, L., Feng, Y., Han, X., \& He, X. (2014). Sorafenib in metastatic radioactive iodine-refractory differentiated thyroid cancer: A pilot study. Molecular and Clinical Oncology, 2(1), 87-92.

Llovet, J. M., Ricci, S., Mazzaferro, V., Hilgard, P., Gane, E., Blanc, J. F., ... Bruix, J., for the SHARP Investigators Study Group. (2008). Sorafenib in advanced hepatocellular carcinoma. The New England Journal of Medicine, 359(4), 378-390.

Llovet, J. M., Villanueva, A., Lachenmayer, A., \& Finn, R. S. (2015). Advances in targeted therapies for hepatocellular carcinoma in the genomic era. Nature Reviews Clinical Oncology, 12(8), 436-436.

Llovet, J. M., Zucman-Rossi, J., Pikarsky, E., Sangro, B., Schwartz, M., Sherman, M., \& Gores, G. (2016). Hepatocellular carcinoma. Nature Reviews Diseases Primers, 2, 16018.

Maiuri, M. C., Le Toumelin, G., Criollo, A., Rain, J. C., Gautier, F., Juin, P., ... Kroemer, G. (2007). Functional and physical interaction between Bcl$\mathrm{X}(\mathrm{L})$ and a BH3-like domain in Beclin-1. The EMBO Journal, 26(10), 2527-2539. 
Marquez, R. T., \& Xu, L. (2012). Bcl-2:Beclin 1 complex: Multiple, mechanisms regulating autophagy/apoptosis toggle switch. American Journal of Cancer Research, 2(2), 214-221.

McCullough, K. D., Martindale, J. L., Klotz, L. O., Aw, T. Y., \& Holbrook, N. J. (2001). Gadd153 sensitizes cells to endoplasmic reticulum stress by down-regulating $\mathrm{Bcl} 2$ and perturbing the cellular redox state. Molecular and Cellular Biology, 21(4), 1249-1259.

Nakamura, T., \& Sakamoto, K. (2008). Forkhead transcription factor FOXO subfamily is essential for reactive oxygen species-induced apoptosis. Molecular and Cellular Endocrinology, 281(1-2), 47-55.

O'Reilly, K. E., Rojo, F., She, Q. B., Solit, D., Mills, G. B., Smith, D., ... Rosen, N. (2006). mTOR inhibition induces upstream receptor tyrosine kinase signaling and activates Akt. Cancer Research, 66(3), 1500-1508.

Oberstein, A., Jeffrey, P. D., \& Shi, Y. (2007). Crystal structure of the Bcl$\mathrm{XL}-$ Beclin 1 peptide complex: Beclin 1 is a novel $\mathrm{BH} 3$-only protein. The Journal of Biological Chemistry, 282(17), 13123-13132.

Ogata, M., Hino, S., Saito, A., Morikawa, K., Kondo, S., Kanemoto, S., ... Imaizumi, K. (2006). Autophagy is activated for cell survival after endoplasmic reticulum stress. Molecular and Cellular Biology, 26(24), 9220-9231.

Ou, D. L., Shen, Y. C., Yu, S. L., Chen, K. F., Yeh, P. Y., Fan, H. H., ... Cheng, A. L. (2010). Induction of DNA damage-inducible gene GADD45beta contributes to sorafenib-induced apoptosis in hepatocellular carcinoma cells. Cancer Research, 70(22), 9309-9318.

Park, K. J., Lee, S. H., Lee, C. H., Jang, J. Y., Chung, J., Kwon, M. H., \& Kim, Y. S. (2009). Upregulation of Beclin-1 expression and phosphorylation of $\mathrm{Bcl}-2$ and $\mathrm{p} 53$ are involved in the JNK-mediated autophagic cell death. Biochemical and Biophysical Research Communications, 382(4), 726-729.

Pichard, L., Raulet, E., Fabre, G., Ferrini, J. B., Ourlin, J. C., \& Maurel, P. (2006). Human hepatocyte culture. Methods in Molecular Biology, 320, 283-293.

Prieto-Domínguez, N., Ordóñez, R., Fernández, A., García-Palomo, A., Muntané, J., González-Gallego, J., \& Mauriz, J. L. (2016). Modulation of autophagy by sorafenib: Effects on treatment response. Frontiers in Pharmacology, 7, 151

Puthalakath, H., O'Reilly, L. A., Gunn, P., Lee, L., Kelly, P. N., Huntington, N. D., ... Strasser, A. (2007). ER stress triggers apoptosis by activating BH3-only protein Bim. Cell, 129(7), 1337-1349.

Rahmani, M., Davis, E. M., Bauer, C., Dent, P., \& Grant, S. (2005). Apoptosis induced by the kinase inhibitor BAY 43-9006 in human leukemia cells involves down-regulation of $\mathrm{Mcl}-1$ through inhibition of translation. The Journal of Biological Chemistry, 280(42), 35217-35227.

Rashid, H. O., Yadav, R. K., Kim, H. R., \& Chae, H. J. (2015). ER stress: Autophagy induction, inhibition and selection. Autophagy, 11(11), 1956-1977.

Rodríguez-Arribas, M., Pizarro-Estrella, E., Gómez-Sánchez, R., YakhineDiop, S. M. S., Gragera-Hidalgo, A., Cristo, A., ... Fuentes, J. M. (2016). IFDOTMETER: A new software application for automated immunofluorescence analysis. Journal of Laboratory Automation, 21(2), 246-259.

Sanyal, A. J., Yoon, S. K., \& Lencioni, R. (2010). The etiology of hepatocellular carcinoma and consequences for treatment. The Oncologist, 15(Suppl 4), 14-22.

Sauzay, C., Louandre, C., Bodeau, S., Anglade, F., Godin, C., Saidak, Z., ... Galmiche, A. (2018). Protein biosynthesis, a target of sorafenib, interferes with the unfolded protein response (UPR) and ferroptosis in hepatocellular carcinoma cells. Oncotarget, 9(9), 8400-8414.

Shi, Y. H., Ding, Z. B., Zhou, J., Hui, B., Shi, G. M., Ke, A. W., ... Fan, J. (2011). Targeting autophagy enhances sorafenib lethality for hepatocellular carcinoma via ER stress-related apoptosis. Autophagy, 7(10), 1159-1172

Shimizu, S., Takehara, T., Hikita, H., Kodama, T., Tsunematsu, H., Miyagi, T., ... Hayashi, N. (2012). Inhibition of autophagy potentiates the antitumor effect of the multikinase inhibitor sorafenib in hepatocellular carcinoma. International Journal of Cancer, 131(3), 548-557.

Szegezdi, E., Logue, S. E., Gorman, A. M., \& Samali, A. (2006). Mediators of endoplasmic reticulum stress-induced apoptosis. EMBO Reports, 7(9), 880-885.

Torre, L. A., Bray, F., Siegel, R. L., Ferlay, J., Lortet-Tieulent, J., \& Jemal, A. (2015). Global cancer statistics, 2012. CA: A Cancer Journal for Clinicians, 65(2), 87-108.

Urano, F., Wang, X., Bertolotti, A., Zhang, Y., Chung, P., Harding, H. P., \& Ron, D. (2000). Coupling of stress in the ER to activation of JNK protein kinases by transmembrane protein kinase IRE1. Science, 287(5453), 664-666.

Verfaillie, T., Salazar, M., Velasco, G., \& Agostinis, P. (2010). Linking ER stress to autophagy: Potential implications for cancer therapy. International Journal of Cell Biology, 2010, 930509-930519.

Villanueva, A., \& Llovet, J. M. (2012). Second-line therapies in hepatocellular carcinoma: Emergence of resistance to sorafenib. Clinical Cancer Research, 18(7), 1824-1826.

Wan, X., Harkavy, B., Shen, N., Grohar, P., \& Helman, L. J. (2007). Rapamycin induces feedback activation of Akt signaling through an IGF-1R-dependent mechanism. Oncogene, 26(13), 1932-1940.

Wei, Y., Pattingre, S., Sinha, S., Bassik, M., \& Levine, B. (2008). JNK1mediated phosphorylation of $\mathrm{Bcl}-2$ regulates starvation-induced autophagy. Molecular Cell, 30(6), 678-688.

Wilhelm, S. M., Carter, C., Tang, L., Wilkie, D., McNabola, A., Rong, H., ... Trail, P. A. (2004). BAY 43-9006 exhibits broad spectrum oral antitumor activity and targets the RAF/MEK/ERK pathway and receptor tyrosine kinases involved in tumor progression and angiogenesis. Cancer Research, 64(19), 7099-7109.

Willis, S. N., Fletcher, J. I., Kaufmann, T., van Delft, M. F., Chen, L., Czabotar, P. E., ... Huang, D. C. S. (2007). Apoptosis initiated when $\mathrm{BH} 3$ ligands engage multiple $\mathrm{Bcl}-2$ homologs, not Bax or Bak. Science, 315(5813), 856-859.

Yi, P., Higa, A., Taouji, S., Bexiga, M. G., Marza, E., Arma, D., ... Chevet, E. (2012). Sorafenib-mediated targeting of the AAA(+) ATPase p97/VCP leads to disruption of the secretory pathway, endoplasmic reticulum stress, and hepatocellular cancer cell death. Molecular Cancer Therapeutics, 11(12), 2610-2620.

Yu, C., Bruzek, L. M., Meng, X. W., Gores, G. J., Carter, C. A., Kaufmann, S. H., \& Adjei, A. A. (2005). The role of Mcl-1 downregulation in the proapoptotic activity of the multikinase inhibitor BAY 43-9006. Oncogene, 24(46), 6861-6869.

Yun, H., Kim, H. S., Lee, S., Kang, I., Kim, S. S., Choe, W., \& Ha, J. (2009). AMP kinase signaling determines whether c-Jun $\mathrm{N}$-terminal kinase promotes survival or apoptosis during glucose deprivation. Carcinogenesis, 30(3), 529-537.

\section{SUPPORTING INFORMATION}

Additional supporting information may be found online in the Supporting Information section at the end of the article.

How to cite this article: Rodríguez-Hernández MA, González R, de la Rosa ÁJ, et al. Molecular characterization of autophagic and apoptotic signaling induced by sorafenib in liver cancer cells. J Cell Physiol. 2019;234:692-708.

https://doi.org/10.1002/jcp.26855 